\title{
Improving the biological control of Persicaria perfoliata (Polygonaceae) using Rhinoncomimus latipes Korotyaev (Coleoptera: Curculionidae)
}

Jaewon Kim

West Virginia University, jk0112@mix.wvu.edu

Follow this and additional works at: https://researchrepository.wvu.edu/etd

Part of the Aeronautical Vehicles Commons, Botany Commons, Entomology Commons, and the Weed Science Commons

\section{Recommended Citation}

Kim, Jaewon, "Improving the biological control of Persicaria perfoliata (Polygonaceae) using Rhinoncomimus latipes Korotyaev (Coleoptera: Curculionidae)" (2020). Graduate Theses, Dissertations, and Problem Reports. 7873.

https://researchrepository.wvu.edu/etd/7873

This Thesis is protected by copyright and/or related rights. It has been brought to you by the The Research Repository @ WVU with permission from the rights-holder(s). You are free to use this Thesis in any way that is permitted by the copyright and related rights legislation that applies to your use. For other uses you must obtain permission from the rights-holder(s) directly, unless additional rights are indicated by a Creative Commons license in the record and/ or on the work itself. This Thesis has been accepted for inclusion in WVU Graduate Theses, Dissertations, and Problem Reports collection by an authorized administrator of The Research Repository @ WVU. For more information, please contact researchrepository@mail.wvu.edu. 


\title{
Improving the biological control of Persicaria perfoliata (Polygonaceae) using Rhinoncomimus latipes Korotyaev (Coleoptera: Curculionidae)
}

\author{
Jaewon Kim \\ Thesis submitted \\ to the Davis College of Agriculture, Natural Resources and Design \\ at West Virginia University \\ in partial fulfillment of requirements for the degree of \\ Master of Science in \\ Plant and Soil Sciences - Entomology
}

Yong-Lak Park, Ph.D., Chair

Cynthia Huebner, Ph.D.

Insu Hong, Ph.D.

Division of Plant and Soil Sciences

Morgantown, West Virginia

2020

Keywords: Persicaria perfoliata, Rhinoncomimus latipes Korotyaev, biological control, unmanned aircraft system, 3d-printing, plant composition, multivariate analysis

Copyright 2020 Jaewon Kim 


\section{ABSTRACT \\ Improving the biological control of Persicaria perfoliata (Polygonaceae) using \\ Rhinoncomimus latipes Korotyaev (Coleoptera: Curculionidae)}

\section{Jaewon Kim}

Persicaria perfoliata (L.) H. Gross (Polygonaceae; Mile-a-minute weed) is a rapid-growing invasive vine introduced from eastern Asia to northeastern United States in the 1930s. This vine has been invaded in disturbed areas and reforestation sites in 15 states in the U.S. and forms dense, monocultural patches that may inhibit natural forest regeneration. To control this weed, a host-specific biocontrol agent, Rhinoncomimus latipes Korotyaev (Coleoptera: Curculionidae) has been released in the $P$. perfoliata invaded states in the U.S. during the past 15 years. Currently, $R$. latipes is released by hand to the invaded area where the presence of the weed is readily detected. However, the hand-release method is not applicable to weed patches located in hard-to-access areas. Moreover, successful management of a target invasive species using biocontrol and/or other methods may not lead to recovery of native species. Understanding the plant composition of invaded sites prior to management may prevent invasion of other exotic weeds currently present in lower abundance. This study was conducted to improve weed management of $P$. perfoliata using UAS for spatially-targeted release of $R$. latipes on $P$. perfoliata patches in hard-to-access areas and to evaluate the plant species composition of invaded sites to determine likely species assemblies and successional trajectories after removal of $P$. perfoliata.

First, we developed a spatially-targeted biocontrol strategy by using an unmanned aircraft system (UAS) for the detection of $P$. perfoliata and release of $R$. latipes. A rotary wing UAS was flown at 15 different altitudes to determine the detectability of $P$. perfoliata patches and, the presence of $P$. perfoliata was confirmed by a ground survey. In addition, we developed a new insect-release system that would be environmentally-friendly and easy to handle in the field. The release system that housed $R$. latipes for aerial release was 3-D printed with biodegradable polyvinyl alcohol (PVA), and tests were conducted to determine the ability of $R$. latipes to escape the pod and assess their post-release mortality and feeding ability of $R$. latipes. Persicaria perfoliata patches were readily detectable on the aerial images taken at $\leq$ 15 -m flight altitudes. More than $98 \%$ of $R$. latipes $(\mathrm{n}=118)$ successfully escaped from the release system within 24 hours after aerial deployment. There were no significant $(\mathrm{P}>0.05)$ effects of PVA exposure on the mortality and feeding ability of $R$. latipes.

Second, we conducted a plant community survey on $P$. perfoliata dominated sites. We compared the species composition of $P$. perfoliata-dominated (dominated) patches and adjacent patches where $P$. perfoliata was not dominant (not-dominated) within an environmentally homogeneous site infested with $P$. perfoliata. This study was conducted in two invaded sites (JS and RV) in southwestern Pennsylvania. The relative importance of all vascular plant species (combined cover and frequency values), richness, diversity, and evenness were determined for each plot type. Significant differences in species composition in the two plot types were determined using nonmetric multidimensional scaling and a multiresponse permutation procedure. Indicator species within the plot types were also calculated. There were a total of 36 and 26 plant species from the JS and RV sites, respectively. The dominated plots had lower species diversity and richness than the nondominated plots. The species compositions between the two plot types differed significantly, though site differences were stronger. In addition, an exotic invader, 
Microstegium vimineum, and native weed, Ambrosia artemisiifolia, were the most important species in the nondominant plots in JS and RV sites, respectively.

Those results of this study suggest that the comprehensive management including utilization of UAS as a site-specific deployment system of $R$. latipes and understanding potentially coexisting native and exotic plant species within the $P$. perfoliata invaded sites will help successful control of the target weed and restoration of invaded sites. 


\section{Acknowledgement}

I would like to thank my advisor, Dr. Yong-Lak Park, for being a wonderful teacher and mentor for the past three years. I am also grateful to have had the opportunity to work with Dr. Cynthia Huebner from USDA Forest Service and Dr. Insu Hong, the members of my M.S.

Committee. Their input and advice improved my research and helped guide my development as a young scientist. I thank the WVU Entomology lab members and collaborators from the engineering department for their many helpful conversations and suggestions about this research. I am grateful to Vicki Kondo for her assistance with laboratory work, and Braley Burke, my great colleague during M.S., for being a private English teacher and a good competitor. I thank Dr. Richard Reardon for supporting this research. In addition, I'd like to thank Rebecca Trigger and Harold Thistle for supporting this research by allowing me to use their properties and equipment.

On a more personal note, I would like to thank all of my friends I have met throughout my graduate experience and my former officers of the West Virginia University Korean Student Association for assistance with club activities. Most of all, I am eternally grateful for my beloved family, Eun Ja Kim, Hyung Sop Kim, Soo Jin Kim and my brother-in-law, Yongjun Shin for their constant love and support. 


\section{TABLE OF CONTENTS}

Chapter 1 Introduction

Thesis organization 1

General Introduction 1

Objectives of Study $\quad 2$

Literature Review 3

$\begin{array}{ll}\text { Literature Cited } & 7\end{array}$

Chapter 2 Spatially-targeted biological control of mile-a-minute weed using Rhinoncomimus latipes (Coleoptera: Curculionidae) and an unmanned aircraft system

$\begin{array}{ll}\text { Abstract } & 16\end{array}$

Materials and Methods $\quad 20$

Results 23

Discussion 24

$\begin{array}{ll}\text { Literature Cited } & 27\end{array}$

Chapter 3 Persicaria perfoliata's (Polygonaceae; Mile-a-minute weed) dominated plant communities: a description of species abundances, richness, diversity, and plant composition

$\begin{array}{ll}\text { Abstract } & 41\end{array}$

Materials and Methods $\quad 45$

$\begin{array}{ll}\text { Results } & 48\end{array}$

Discussion 49

Literature Cited $\quad 52$

Chapter 4 General conclusion

$\begin{array}{ll}\text { Conclusion } & 67\end{array}$

Appendices

Appendix 1 


\section{LIST OF TABLES}

Chapter 2 Spatially-targeted biological control of mile-a-minute weed using Rhinoncomimus latipes (Coleoptera: Curculionidae) and an unmanned aerial system

Table 1. Average feeding area (mean $\pm \mathrm{SEM})$ of $R$. latipes in control $(\mathrm{n}=40)$ and PVAexposed $(\mathrm{n}=40)$ group. The unit of measurement was $\mathrm{cm} 2$. No significant differences found between control and PVA-exposed groups $(P>0.05)$.

Chapter 3 Persicaria perfoliata's (Polygonaceae; Mile-a-minute weed) dominated plant communities: a description of species abundances, richness, diversity, and plant composition

Table. 1 Rank of relative importance value of each species high to low in two sites $(P$. perfoliata excluded).

Table. 2 MRPP results for differences between sites and plot types. ( $A$ : the chance-correct within-group agreement; when all items identical with groups, $A=1$, if heterogeneity within groups equals expectation by chance, $A=0)(\mathrm{JS}=$ Jefferson; RV = Rogersville). 60 Table. 3 Indicator species with $P<0.05$ in each group. (IV = Indicator value). No indicator species was detected in JS site from ISA, while Ambrosia artemisiifolia from nondominated plots and Celastrus orbiculatus from dominated plots were detected in RV site from ISA. 


\section{TABLE OF FIGURES}

Chapter 1 Introduction

Fig. 1. A) A patch of P. perfoliata and B) the weed covering trees and shrubs.

Chapter 2 Spatially-targeted biological control of mile-a-minute weed using Rhinoncomimus latipes (Coleoptera: Curculionidae) and an unmanned aerial system

Fig. 1. Schematic diagram of aerial-release systems and an operational protocol with UAS. $R$. latipes adults will be loaded into a bug pod by using a vacuum. The pod is attached to a UAS dispense (Park et al. 2018). UAS are flown to detect a $P$. perfoliata patch and deploy the bug pod over the $P$. perfoliata patch.

Fig. 2. Schematic design of the bug pod using Solidworks ${ }^{\circledR}$. A, side view; B, perspective view; $\mathrm{C}$, bottom lid for loading the weevils; $\mathrm{D}$, top lid with a 3-mm hole for $R$. latipes to escape after aerial release.

Fig. 3. Size estimation based on the width and length of $R$. latipes using a digital microscope to determine precise design of bug pod.

Fig. 4. Example bug pod printed by 3-D printer using PVA. A, view from the bottom of the bug pod with pin holes for ventilation; $\mathrm{B}$, view from the top of the bug pod with an exit hole that is covered with a pieces of $P$. perfoliata leaf; $\mathrm{C}$, a vacuum to load $R$. latipes into the bug pod.

Fig. 5. Detectability of $P$. perfoliata by UAS flown at different altitudes $(\mathrm{n}=13$ per flight altitude).

Fig. 6. Detectability of $P$. perfoliata patches (left) based on aerial images acquired from UAS at different flight altitudes. Note that $P$. perfoliata could not be detected the image taken by UAS at $>25 \mathrm{~m}$ above the ground.

Chapter 3 Persicaria perfoliata's (Polygonaceae; Mile-a-minute weed) dominated plant communities: a description of species abundances, richness, diversity, and plant composition

Fig. 1. The plots and patches in various size for potential plots selection. Within patches (Grey) that were $<10 \mathrm{~m}^{2}$, one $1 \mathrm{~m}^{2}$ circular plot was fit for potential vegetation sampling as the P. perfoliata dominated plot (Black), and two $1-\mathrm{m}^{2}$ plots were fit in patches $>10$ $\mathrm{m}^{2} \&<30 \mathrm{~m}^{2}$, and three $1-\mathrm{m}^{2}$ plots for $>30 \mathrm{~m}^{2}$. After random selection of dominated plots, a nondominated plot (white) was established out of the patch but within 5-m distance.

Fig. 2. The schematic diagram of $1 \mathrm{~m}^{2}$ plot and quarters established in the plot. Cover was estimated visually for each plant species by using $0.005 \mathrm{~m}^{2}$ circle.

Fig. 3. A stable two-dimensional nonmetric multidimensional scaling ordination for Beals smoothed combined dataset grouped by sites (final NMS stress $=5.93$, final instability $<$ $0.000001, p=0.004,250$ real and 250 randomized run, Sorensen distance measure). Dissimilarity between dominated and nondominant plots in JS (Dominated plots: Red; Nondominated plots: Blue) is relatively higher than those in RV (Dominated plots: Orange; Nondominated plots: Sky blue).

Fig. 4. Separate two-dimensional NMS ordination (A: axis $1 \& 3$ for JS; B: axis $1 \& 2$ for $\mathrm{RV}$ ) for Beals smoothed data grouped by plot type (JS: final NMS stress $=8.1$, final instability $<0.000001, p=0.004,250$ real and 250 randomized run, Sorensen distance 
measure; RV: final NMS stress $=7.2$, final instability $<0.000001, p=0.004250$ real and 250 randomized run, Sorensen distance measure).

Fig. 5. Mean \pm S.E. of species A) richness, B) Shannon's diversity index, and C) evenness for the summery of combined site data. $\mathrm{D}=$ P. perfoliata dominated; $\mathrm{N}=$ nondominated; $\mathrm{J}=$ Jefferson site, $\mathrm{R}=$ Rogersville site. Different letters indicate statistically significant differences among treatments (ANOVA, HSD). Statistical significance was determined at the alpha level of 0.05 . 


\section{CHAPTER 1: INTRODUCTION}

\section{Thesis organization}

This thesis is organized into four chapters. Chapter 1 is a general introduction to the study and a literature review. Chapter 2 describes spatially-targeted biological control of mile-a-minute weed using Rhinoncomimus latipes (Coleoptera: Curculionidae) and an unmanned aircraft system. Chapter 3 describes species abundance, richness, diversity, and plant composition in two Persicaria perfoliata (Polygonaceae; Mile-a-minute weed) dominated plant communities. Chapter 4 provides a general conclusion for this study. This thesis was prepared according to the publication guidelines established by the Entomological Society of America.

\section{General Introduction}

Persicaria perfoliata (Polygonaceae), is an introduced weed threatening native flora in the United States. It has steadily spread across at least 15 states in the Mid-Atlantic and the east coast, from New Hampshire to North Carolina, invading disturbed areas in response to anthropogenic activities, including recently harvested forests and other openings (Hough-Goldstein et al. 2015, EDDMapS 2020). As the weed grows rapidly in early spring and creates monoculture patches, it appears capable of outcompeting native plant species for resources (i.e., light availability, water) and negatively impacting the ecosystem processes of the invaded area. Additionally, its high reproductive potential and ability to form a seedbank (up to 6-yr viability) makes weed management including physical or mechanical removal, and chemical control time-consuming and challenging. Although biological control using the weevil, Rhinoncomimus latipes (Coleoptera: Curculionidae), has been directly released in P. perfoliata populations and successful in several locations (Hough-Goldstein et al. 2009, Hudson et al. 2017), P. perfoliata's patchy distribution in large landscapes located in inaccessible areas makes treatment only feasible if the patches can be spatially-targeted and $R$. latipes released with some precision. 
My research was designed to improve current biological control of $P$. perfoliata by implementing the aerial release of $R$. latipes using customized small Unmanned Aircraft System (UAS; a.k.a. drone). There were two main objectives in my research: 1) utilization of 3-D printing and designing technology to make a 'bug pod', a cylinder-shaped container housing $R$. latipes that is designed for easy loading, easy unloading after aerial-drop, and that is biodegradable; the bug pods printed out of polyvinyl alcohol (PVA) filament were used for deploying $R$. latipes on the $P$. perfoliata patches, and 2) analysis of $P$. perfoliata-infested sites to determine patterns in species composition including the possible existence of coexisting or competitive native or other exotic plant species, which may then be likely to populate the site once $P$. perfoliata is removed.

\section{Objectives of Study}

The goal of this research is to improve weed management of $P$. perfoliata using UAS as a deployment system of $R$. latipes on $P$. perfoliata patches in hard-to-access areas and to evaluate the plant species composition of invaded sites to determine likely species assemblies or successional trajectories after removal of $P$. perfoliata.

1. Spatially-targeted biological control of P. perfoliata using R. latipes (Coleoptera: Curculionidae) and an unmanned aerial system (Chapter 2).

2. Persicaria perfoliata's (Polygonaceae; Mile-a-minute weed) dominated plant communities: a description of species abundances, richness, diversity, and plant composition (Chapter 3). 


\section{Literature Review}

\section{Life history and management of P. perfoliata in the United States}

Mile-a-minute weed, Persicaria perfoliata (L.) H. Gross (Polygonaceae), is a rapidly-growing non-native plant invading the northeastern United States (Kumar and DiTommaso 2005, HoughGoldstein et al. 2012a, Hough-Goldstein et al. 2015). The first record of the weed was reported in 1890 in Oregon, but the weed did not establish in the area (Cusick and Ortt 1987). In the 1930s, P. perfoliata was accidently introduced in a nursery in York County, Pennsylvania and is currently distributed in 15 states ranging from New Hampshire to North Carolina (Moul 1948, Hough-Goldstein et al. 2008, Miller et al. 2018, EDDMapS 2020). Persicaria perfoliata can grow up to $6 \mathrm{~m}$ in one growing season (Oliver 1997). This vine occurs primarily in disturbed riparian sites within its native countries (China, Korea, Japan and Philippines), but invades forest edges, open fields, and other disturbed areas (i.e. construction site, roadsides, utility rights-of-way) forming high density of patches in the United States (Fig.1) (Cusick and Ortt 1987, Hough-Goldstein et al. 2015). Documented impacts of $P$. perfoliata include reducing native plant diversity, preventing forest regeneration, and interfering with recreational use of natural areas (Oliver 1997; Wu et al. 2002, Hough-Goldstein et al. 2012a; Hough-Goldstein et al. 2015). Unlike in its native range, $P$. perfoliata in northeastern United States is not suppressed by insect herbivores that specifically feed on P. perfoliata or generalist herbivores that cause severe damage (Ding et al. 2004). This release from enemies may give $P$. perfoliata a competitive advantage over any associated native species in P. perfoliata's invasive and Crawley 2002).

Current methods of $P$. perfoliata management include the use of natural enemies, physical or mechanical removal, cultural methods, and herbicides. Landscape-scale infestations of the weed makes these control techniques time-consuming, expensive, and inefficient. In addition, small rodents, birds, deer, and waterways allow the seeds to travel extensive distances making the weed control more spatially complex (Mountain 1989, Hough-Goldstein et al. 2015). Moreover, the seeds can persist and remain 
viable within the soil for six years (Hough-Goldstein et al. 2015) suggesting the need for a continuous and long-term temporal management.

\section{Introduction and life history of R. latipes to the United States}

To identify the natural enemies associated with P. perfoliata in the United States, Wheeler and Mengel (1984) conducted a survey in southcentral Pennsylvania in 1981-1983. They reported 34 insect species in five orders and 15 families. However, all the insects were ectophagous causing only minor feeding damage on P. perfoliata; there were no leafminers, stem borers, internal fruit feeder, or gall makers. Another survey searching natural enemies of $P$. perfoliata was carried out in northeastern and southwest China, where the climate is similar with that of the mid-Atlantic region of the United States. Those regions in China were regarded as the origin of the family Polygonaceae (Ding et al. 2004). A total of 111 phytophagous species in six orders and 29 families associated with P. perfoliata were reported. Ding et al. (2004) found that the mile-a-minute weevil, Rhinoncomimus latipes Korotyaev (Coleoptera: Curculionidae) was the most promising biological control agent of P. perfoliata.

Rhinoncomimus latipes was introduced to North America in 2004 for a classical biological control on P. perfoliata (Colpetzer et al. 2004a). Previous studies showed that $R$. latipes exclusively fed and laid eggs on $P$. perfoliata, although it could feed on several related species in no-choice tests (Colpetzer et al. 2004b, Frye et al. 2010). The results from a supervised release in five states of the United States and subsequent surveys have shown that $R$. latipes could suppress not only the growth and dispersal of $P$. perfoliata but the seed production and fruit maturation (Hough-Goldstein et al. 2009, Smith et al. 2014). Mass production of $R$. latipes has been successful at the Phillip Alampi Beneficial Insect Rearing Laboratory, New Jersey Department of Agriculture since 2004, and over 600,000 R. latipes were shipped and released in 11 states between 2004 and 2014 (Hough-Goldstein et al. 2015).

$R$. latipes reproduces 3 to 4 generations per year in the United States and lays 2 to 4 eggs per day primarily on stems and leaves of $P$. perfoliata (Colpetzer et al. 2004a, Lake 2007). The complete cycle from egg to adult takes about 26 days under laboratory condition (Price et al. 2003). Frye et al. (2010) 
showed that $96.5 \%$ of $R$. latipes were found on the P. perfoliata within $44 \mathrm{~h}$ after the release without feeding damage on non-target plants. Based on highly selective host specificity and oviposition preference on $P$. perfoliata, $R$. latipes is a highly promising biological control agent in mid-eastern United States.

Dispersal ability of $R$. latipes was studied by Lake et al. (2011). They found that $R$. latipes dispersed up to $2.9 \mathrm{~m}$ per week and they presumed that $R$. latipes dispersed through flight because $R$. latipes were found about 600-760 m away from the release point within 14 months (Lake et al. 2011). Also, a releasing point should be considered because it had been observed that $R$. latipes were more attracted to $P$. perfoliata growing in full sun and preferred sunny areas to shaded areas (Hough-Goldstein and LaCoss 2012b, Smith and Hough-Goldstein 2013). Current $R$. latipes release is restricted in the weed patches in easy-to-access areas. Therefore, an areawide or landscape-scale release of $R$. latipes should be considered to distribute $R$. latipes more effectively.

\section{Unmanned Aircraft System for Aerial-release of Biological Control Agent}

Unmanned Aircraft System (UAS) includes one or multiple types of unmanned aircraft vehicles, the ground-based pilot, and the datalink and sensory array between the pilot and the vehicle (Blom 2010). The UAS can be classified into two types based on its shape: a fixed-wing and rotary-wing. The fixedwing UAS can perform generally longer flights with the forward thrust and lift, while the rotary-wing UAS can perform relatively short flight but can take-off vertically by the thrust generated by multiple motors (Lee and Choi 2015).

The UAS has been utilized in various agricultural applications for the detection and management of pests. Gonzalez et al. (2017) developed UAS-involved autonomous robotic systems for effective weed management. The aerial-release techniques for Trichogramma spp. (Hymenoptera: Trichogrammatidae), a biological control agent of pests in rice paddy fields, was successfully developed by Li et al. (2013). Currently, the release of $R$. latipes and other biological control agents have relied on manual release (De Clerck-Floate et al. 2005, Hough-Goldstein et al. 2009). No research has been conducted on the aerial- 
release of $R$. latipes except Park et al. (2018) who developed a framework of aerial-release system of natural enemies using UAS.

\section{D-printing of Entomologically Designed Bug pod}

The 3-D printing and Additive Manufacturing is a prospective technology that could surmount the last two centuries of approaches to design and manufacturing with profound implications ranging from society to environment (Campbell et al., 2011). Not like subtractive manufacturing (i.e. subtracting or cutting out a material from a large raw material), 3-D printing creates products from the bottom-up by adding material layer by layer. Application of this technology for entomological research have rarely been explored, with a study conducted by Domingue et al. (2015) using 3d printed decoy mimicking morphology and color of emerald ash borer as being one of the few.

\section{Management of Biological Invasions}

Biological invasions of non-native species are recognized as a major environmental issue and global threat to species diversity (Vilà and Weiner, 2004, Hejda et al. 2009). Invasive species can reduce or displace native species and may even alter ecosystem functions (Scofield 1989). Disturbance is a crucial component of invasion of non-native and weedy plant species (Hobbs and Huenneke 1992) and this disturbance associated with human activities resulting in alteration of abiotic conditions increases the invasibility of ecosystems (Gross et al. 2005, Catford et al. 2012) in such a way that promoting introduction of invasive species. Biological invasions can result in severe ecological damage unless weed management is performed at key times with adequate efficacy. Invasive plant management includes three steps: prevention, eradication, and control (Hulme 2006, McGeoch et al. 2010). Each step requires different management responses and approaches specific to the invasion process (Hulme 2006). For instance, prevention is best achieved using border controls and quarantine measures determined by a risk assessment based on the potential invasiveness of a species (Leung et al. 2002), while early detection and rapid response work best for eradication of early-establishing invaders. In contrast, general control 
measures (biocontrol, herbicide, mechanical removal, fire) are necessary for long-established invasive plants (Wittenberg and Cock 2001).

\section{Plant Interactions within Invaded Communities}

Species interactions between native and non-native plants in invaded ecosystems include coexistence (Godoy 2019), competition (Meiners 2007, Flory and Clay 2010), and facilitation. Such interactions may then result in novel communities or invasional meltdowns (Simberloff and Von Holle 1999, Simberloff 2006; Hobbs et al. 2009; Nilsen et al. 2018). Though competition is often assumed to be the dominant interaction between native and nonnative plants with invasive plants being the better competitor, some native species are the better competitor, some natives may facilitate invasive plants or vice versa, and some species coexist by occupying their own niche and potentially benefitting other trophic levels (Stout and Tiedeken 2017; Godoy 2019).

The distribution of $P$. perfoliata in various landscapes has a tendency to show a high degree of patchiness, encroaching on desirable vegetation (Hough-Goldstein et al., 2015). The effectiveness of current biological control using $R$. latipes could be increased by site-specific release on the patches based on spatial distribution of the weed in landscapes. Moreover, the initial amount of release is positively related to the probability of population establishment (Grevstad, 1999) and thus a spatially-targeted release of biological control agent will make the weed management more effective.

\section{Literature Cited}

Blom J. 2010. Unmanned aerial systems: a historical perspective. Combat Studies Institute Press, US Army Combined Arms Center, Kansas. pp. 2-3.

Campbell, T., C. Williams, O. Ivanova, and B. Garrett. 2011. Could 3D printing change the world? Technologies, potential, and implications of additive manufacturing. Atl. Counc. Washington, DC. 
Catford, J. A., P. A. Vesk, D. M. Richardson, and P. Pyšek. 2012. Quantifying levels of biological invasion: Towards the objective classification of invaded and invasible ecosystems. Glob. Chang. Biol. 18: 44-62.

Colpetzer, K., J. Hough-Goldstein, K. R. Harkins, and M. T. Smith. 2004a. Feeding and oviposition behavior of Rhinoncomimus latipes Korotyaev (Coleoptera: Curculionidae) and its predicted effectiveness as a biological control agent for Polygonum perfoliatum L. (Polygonales: Polygonaceae). Environ. Entomol. 33: 990-996.

Colpetzer, K., J. Hough-Goldstein, J. Ding, and W. Fu. 2004b. Host specificity of the Asian weevil, Rhinoncomimus latipes Korotyaev (Coleoptera: Curculionidae), a potential biological control agent of mile-a-minute weed, Polygonum perfoliatum L. (Polygonales: Polygonaceae). Biol. Control. 30: $511-522$.

Cusick, A. W., and M. Ortt. 1987. Polygonum perfoliatum L. (Polygonaceae): A significant new weed in the Mississippi drainage. SIDA. 12: 246-249.

De Clerck-Floate, R. A., B. Wikeem, and R. S. Bourchier. 2005. Early establishment and dispersal of the weevil, Mogulones cruciger (Coleoptera: Curculionidae) for biological control of houndstongue (Cynoglossum officinale) in British Columbia, Canada. Biocontrol Sci. Technol. 15: 173-190.

Ding, J., W. Fu, R. Reardon, Y. Wu, and G. Zhang. 2004. Exploratory survey in China for potential insect biocontrol agents of mile-a-minute weed, Polygonum perfoliatum L., in Eastern USA. Biol. Contr. 30: 487-495.

Domingue, M. J., D. P. Pulsifer, A. Lakhtakia, J. Berkebile, K. C. Steiner, J. P. Lelito, L. P. Hall, and T. C. Baker. 2015. Detecting emerald ash borers (Agrilus planipennis) using branch traps baited with 3D-printed beetle decoys. J. Pest Sci. 88: 267-279. 
EDDMapS, 2020. Early Detection \& Distribution Mapping System. The University of Georgia - Center for Invasive Species and Ecosystem Health. Available from https://www.eddmaps.org/distribution/viewmap.cfm?sub=3065

Flory, S. L., and K. Clay. 2010. Non-native grass invasion suppresses forest succession. Oecologia. 164: $1029-1038$.

Frye, M. J., E. C. Lake, and J. Hough-Goldstein. 2010. Field host-specificity of the mile-a-minute weevil, Rhinoncomimus latipes Korotyaev (Coleoptera: Curculionidae). Biol. Control. 55: 234-240.

Godoy, O. 2019. Coexistence theory as a tool to understand biological invasions in species interaction networks: Implications for the study of novel ecosystems. Funct. Ecol. 33: 1190-1201.

Gonzalez-de-Santos, P., A. Ribeiro, C. Fernandez-Quintanilla, F. Lopez-Granados, M. Brandstoetter, S. Tomic, S. Pedrazzi, A. Peruzzi, G. Pajares, G. Kaplanis, M. Perez-Ruiz, C. Valero, J. del Cerro, M. Vieri, G. Rabatel, and B. Debilde. 2017. Fleets of robots for environmentally-safe pest control in agriculture. Precis. Agric. 18: 574-614.

Grevstad, F. S. 1999. Experimental invasions using biological control introductions: The influence of release size on the chance of population establishment. Biol. Invasions. 1: 313-323.

Gross, K. L., G. G. Mittelbach, and H. L. Reynolds. 2005. Grassland invasibility and diversity: Responses to nutrients, seed input, and disturbance. Ecology. 86: 476-486.

Hejda, M., P. Pyšek, and V. Jarošík. 2009. Impact of invasive plants on the species richness, diversity and composition of invaded communities. J. Ecol. 97: 393-403.

Hobbs, R. J., E. Higgs, and J. A. Harris. 2009. Novel ecosystems: implications for conservation and restoration. Trends Ecol. Evol. 24: 599-605. 
Hobbs, R. J., and L. F. Huenneke. 1992. Disturbance, diversity, and invasion: implications for conservation. Conserv. Biol. 6: 324-337.

Hough-Goldstein J., Lake E., Reardon R., and Wu Y. 2015. Biology and biological control of mile-aminute weed. Morgantown, WV: USDA Forest Service Forest Health Technology Enterprise Team, FHTET-2008-10.

Hough-Goldstein, J., E. Lake, and R. Reardon. 2012a. Status of an ongoing biological control program for the invasive vine, Persicaria perfoliata in eastern North America. BioControl. 57: 181-189.

Hough-Goldstein, J., and S. J. LaCoss. 2012b. Interactive effects of light environment and herbivory on growth and productivity of an invasive annual vine, Persicaria perfoliata. Arthropod. Plant. Interact. 6: $103-112$.

Hough-Goldstein, J., M. A. Mayer, W. Hudson, G. Robbins, P. Morrison, and R. Reardon. 2009. Monitored releases of Rhinoncomimus latipes (Coleoptera: Curculionidae), a biological control agent of mile-a-minute weed (Persicaria perfoliata), 2004-2008. Biol. Control. 51: 450-457.

Hough-Goldstein, J., Schiff, M., Lake, E., \& Butterworth, B. (2008). Impact of the biological control agent Rhinoncomimus latipes (Coleoptera: Curculionidae) on mile-a-minute weed, Persicaria perfoliata, in field cages. Biol. Contr. 46(3): 417-423.

Hudson, W., G. Robbins, J. DeSio, C. Detweiler, R. Strubel, A. Lovero, J. Beetle, and M. Mayer. 2017. Rhinoncomimus latipes (Coleoptera: Curculionidae) as a biological control agent for milea-minute, Persicaria perfoliata in New Jersey. Annual Report. Phillip Alampi Beneficial Insect Laboratory, Division of Plant Industry, New Jersey.

Hulme, P. E. 2006. Beyond control: Wider implications for the management of biological invasions. J. Appl. Ecol. 43: 835-847. 
Keane, R. M., and M. J. Crawley. 2002. Exotic plant invasions and the enemy release hypothesis. Trends Ecol. Evol. 17: 164-170.

Kumar, V., and A. Ditommaso. 2005. Mile-a-Minute (Polygonum perfoliatum): An Increasingly Problematic Invasive Species 1. Weed Technol. 19: 1071-1077.

Lake, E. C., J. Hough-Goldstein, K. J. Shropshire, and V. D'Amico. 2011. Establishment and dispersal of the biological control weevil Rhinoncomimus latipes on mile-a-minute weed, Persicaria perfoliata. Biol. Control. 58: 294-301.

Lake, E. C. 2007. Dispersal, establishment, and impact of the mile-a-minute weevil, Rhinoncomimus latipes Korotyaev (Coleoptera: Curculionidae): a two-year study in southeastern Pennsylvania. M.S. Thesis. University of Delaware, Newark, DE, USA.

Lee, S., and Y. Choi. 2015. Topographic survey at small-scale open-pit mines using a popular rotarywing unmanned aerial vehicle (Drone). J. Korean Soc. Rock Mech. 25: 462-469.

Leung, B., D. M. Lodge, D. Finnoff, J. F. Shogren, M. A. Lewis, and G. Lamberti. 2002. An ounce of prevention or a pound of cure: Bioeconomic risk analysis of invasive species. Proc. R. Soc. B Biol. Sci. 269: 2407-2413.

Li, D., X. Yuan, B. Zhang, Y. Zhao, Z. Song, and C. Zuo. 2013. Report of using unmanned aerial vehicle to release Trichogramma. Chin. J. Biol. Contr. 29: 455-458 (in Chinese with English abstract).

\section{McGeoch, M. A., S. H. M. Butchart, D. Spear, E. Marais, E. J. Kleynhans, A. Symes, J. Chanson,} and M. Hoffmann. 2010. Global indicators of biological invasion: Species numbers, biodiversity impact and policy responses. Divers. Distrib. 16: 95-108. 
Meiners, S. J. 2007. Apparent competition: An impact of exotic shrub invasion on tree regeneration.

Biol. Invasions. 9: 849-855.

Miller, W. R., B. A. Connolly, and D. Cygan. 2018. A New Record of Invasive Mile-A-Minute Vine Persicaria perfoliata (Polygonaceae) In New Hampshire. Rhodora. 120: 179-180.

Moul, E. T. 1948. a dangerous weedy Polygonum in Pennsylvania. Rhodora. 50: 64-66.

Mountain, W. L. 1989. Mile-a-minute (Polygonum perfoliatum L.) update- distribution, biology, and control suggestions. Reg. Hort. 15: 1976-1979.

Nilsen, E. T., C. D. Huebner, D. E. Carr, and Z. Bao. 2018. Interaction between Ailanthus altissima and native Robinia pseudoacacia in early succession: Implications for forest management. Forests. 9.

Okay, J.A.G. 1997. Polygonum perfoliatum: A study of biological and ecological features leading to the formation of a management policy. Ph.D. Dissertation. George Mason University, Fairfax, VA, USA.

Park, Y. L., S. Gururajan, H. Thistle, R. Chandran, and R. Reardon. 2018. Aerial release of Rhinoncomimus latipes (Coleoptera: Curculionidae) to control Persicaria perfoliata (Polygonaceae) using an unmanned aerial system. Pest Manag. Sci. 74: 141-148.

Parker M., and H. Reichard. 1998. Critical issues in invasion biology for conservation science. In: Freidler L. and M. Kareiva. Conservation biology for the coming decade. Chapman and Hall. pp. 283305. 
Price, D. L., J. Hough-Goldstein, and M. T. Smith. 2003. Biology, rearing, and preliminary evaluation of host range of two potential biological control agents for Mile-a-minute weed, Polygonum perfoliatum L. Environ. Entomol. 32: 229-236.

Scofield, E. K. 1989. Effects of introduced plants and animals on island vegetation: Examples from the Galapagos Archipelaga. Conserv. Biol. 3: 227-238.

Simberloff, D. 2006. Invasional meltdown 6 years later: Important phenomenon, unfortunate metaphor, or both? Ecol. Lett. 9: 912-919.

Simberloff, D., and B. Von Holle. 1999. Positive interactions of nonindigenous species. Biol. Invasions. 1: $21-32$.

Smith, J. R., and J. Hough-Goldstein. 2014. Impact of herbivory on mile-a-minute weed (Persicaria perfoliata) seed production and viability. Biol. Control. 76: 60-64.

Smith, J. R., and J. Hough-Goldstein. 2013. Phototaxis, host cues, and host-plant finding in a monophagous weevil, Rhinoncomimus latipes. J. Insect Behav. 26: 109-119.

Stout, J. C., and E. J. Tiedeken. 2017. Direct interactions between invasive plants and native pollinators: evidence, impacts and approaches. Funct. Ecol. 31: 38-46.

Vilà M., and J. Weiner. 2004. Are invasive plant species better competitors than native plant species evidence from pair-wise experiments. Oikos 105: 229-238.

Wheeler, A. G., and S. A. Mengel. 1984. Phytophagous insect fauna of Polygonum perfoliatum, an Asiatic weed recently introduced to Pennsylvania. Ann. Entomol. Soc. Am. 77: 197-202. 
Wittenberg, R., and M. J. W. Cock. 2001. Invasive alien species: A toolkit for best prevention and management practices. CAB International, Wallingford, UK.

Wu Y., Reardon R., and J. Ding. 2002. Mile-a-minute weed. In: Van Driesche, R., Lyon, S., Blossey, B., Hoddle, M., and Reardon, R. Biological control of invasive plants in the Eastern United States. USDA Forest Service Publication FHTHT-2002-04. 

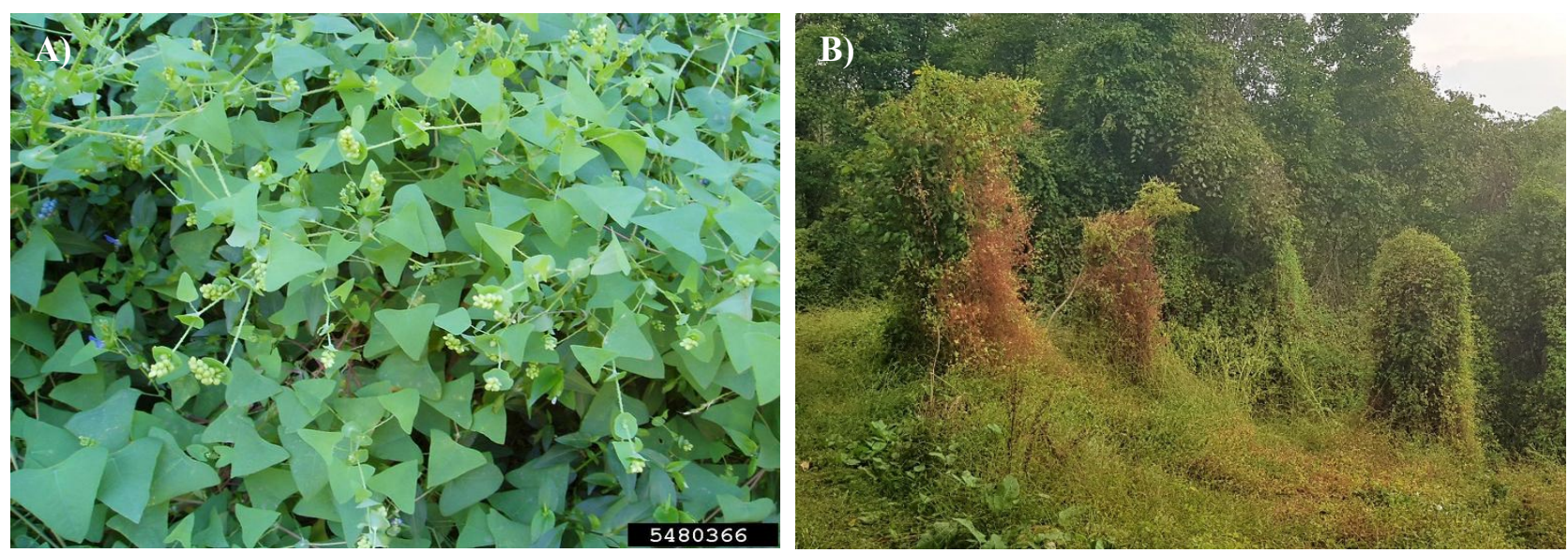

Fig. 1. A) A patch of P. perfoliata and B) the weed covering trees and shrubs. 


\title{
Chapter 2: Spatially-targeted biological control of mile-a-minute weed using Rhinoncomimus latipes (Coleoptera: Curculionidae) and an unmanned aircraft system
}

\begin{abstract}
Rhinoncomimus latipes Korotyaev (Coleoptera: Curculionidae), a host-specific biocontrol agent for Persicaria perfoliata (Polygonaceae), mile-a-minute weed, has been used for 15 years in northeastern and mid-Atlantic United States. Currently R. latipes is released by hand where the presence of the weed is readily detected. However, the hand-release method is not applicable to weed patches spread in hardto-access areas. This study was conducted to develop a spatially-targeted biocontrol strategy by using an unmanned aircraft system (UAS) for the detection of P. perfoliata and aerial release of R. latipes. A rotary-wing UAS was flown at 15 different altitudes to determine the detectability of $P$. perfoliata patches and, the presence of $P$. perfoliata was confirmed by a ground survey. In addition, we developed a new insect-release system that would be environmentally-friendly and easy to handle in the field. The release system that housed $R$. latipes for aerial release was 3-D printed with biodegradable polyvinyl alcohol (PVA), and tests were conducted to determine the ability of $R$. latipes to escape the pod and assess their post-release mortality and feeding ability of $R$. latipes. Persicaria perfoliata patches were readily detectable on the aerial images taken at $\leq 15$-m flight altitudes. More than $98 \%$ of $R$. latipes $(\mathrm{n}=118)$ successfully escaped from the release system within 24 hours after aerial deployment. There were no significant $(\mathrm{P}>0.05)$ effects of PVA exposure on the mortality and feeding ability of $R$. latipes. These results indicate that aerial detection of $P$. perfoliata and deployment of $R$. latipes for biological control in hard-to-access areas can be accomplished using a rotary-wing UAS.
\end{abstract}

Keywords: aerial detection, drone, invasive weed, Persicaria perfoliata, release strategy, UAS 
As many insect pests are spatially aggregated in the agricultural field (Antmann et al. 2008, Rasmussen et al. 2013, Sétamou and Bartels 2015, Fernández-Quintanilla et al. 2017, Nguyen and Nansen 2018), site-specific control of pest hotspots can play a significant role in precision pest management. Filho et al. (2020) states that precision pest management consists of two parts: reflectance-based crop monitoring for identifying pest distribution and precision control systems for delivering control measures. Both technologies provide great opportunities to integrate pest management by utilizing agricultural equipment and manned or unmanned aircrafts. Application of Unmanned Aircraft Systems (UAS; a.k.a. drone) have become a key tool for precision pest management in agriculture and forestry. A number of studies show that the use of UAS could be cost-effective, environmentally-friendly, and advantageous compared to conventional platforms of remote sensing, such as ground-based (e.g., handheld or tractorattached spectral radiometers), manned aerial methods (e.g., airplanes and helicopters), and orbital (e.g., satellite imagery) (Filho et al., 2020).

Mile-a-minute weed, Persicaria perfoliata (L.) H. Gross (Polygonaceae), is a fast-growing invasive weed widely dispersed in the northeastern and mid-Atlantic United States (Kumar and DiTommaso 2005, Hough-Goldstein et al. 2012, Hough-Goldstein et al. 2015). Persicaria perfoliata was first introduced to the northeastern United States accidentally in a nursery in York County, Pennsylvania and is currently distributed over 15 states ranging from New Hampshire to North Carolina (Moul 1948, Hough-Goldstein et al. 2009, Miller et al. 2018, Cheah and Ellis 2019, EDDMaps 2020). This species is found in riparian sites within its native region, including China, Korea, Japan, and Philippines (Wu et al. 2002, Hyatt and Araki 2006). In contrast, P. perfoliata usually invades open fields, forest edges, and disturbed areas (i.e. construction site, roadsides, and utility rights-of-way) in the United States, forming infestations composed of patches with variable connectedness, size, and shape (Cusick and Ortt 1987, Hough-Goldstein et al. 2015). The impacts of $P$. perfoliata include reducing native plant diversity, interfering with recreational use of natural areas, and undermining reforestation and natural forest recovery by overtopping tree seedlings (Wu et al. 2002, Hough-Goldstein et al. 2012). Current methods of P. perfoliata management include biological control, physical or mechanical removal, and pre- and post- 
emergent herbicides (Mountain 1989, Colpetzer et al. 2004a, Gover et al. 2008). However, its rapid growth rate and the viability of seeds for 6-yr in the seed bank (Van Clef and Stiles 2001, Hough Goldstein et al. 2015) make these control techniques time-consuming, expensive, and inefficient. In contrast to its native region, $P$. perfoliata in the United States is not suppressed by native herbivores or pathogens that cause severe damage or form specialized associations of with $P$. perfoliata (Fredericks 2001, Ding et al. 2004).

Following host range testing, a permit was issued by the United States Department of Agriculture Animal and Plant Health Inspection Service Plant Protection and Quarantine for field release of Rhinoncomimus latipes Korotyaev (Coleoptera: Curculionidae) in 2004 (Price et al. 2003, Colpetzer et al. 2004b, Hough-Goldstein et al. 2015). Rhinoncomimus latipes showed a strong host preference and survivorship on $P$. perfoliata over other related Polygonaceae species and economically important plants (e.g., nontarget plants) in no choice tests (Colpetzer et al. 2004b) and open field tests (Frye et al. 2010). Female weevils feed and lay eggs preferentially on capitula (compact flowering head) and less so on other parts of $P$. perfoliata, and this preference increase the larval survivorship because the apical portion including capitula is tenderer to the $R$. latipes larvae to bore into (Colpetzer et al. 2004a). It takes 3-5 days for eggs to hatch and newly hatched larvae bore into the stem. The feeding damage by $R$. latipes adults and stem-boring larvae reduces substantially the growth and reproductive potential of $P$. perfoliata (Smith and Hough-Goldstein 2014). Rhinoncomimus latipes is known to disperse at an average rate of 1.5-2.9 m per week from a release point within a P. perfoliata patch (Lake et al. 2011) and $4.3 \mathrm{~km}$ per year in long-term monitoring (Hough-Goldstein et al. 2009). Although this is a respectable dispersal rate for a small insect, at this rate it would take several decades to reach the current invasion front of $P$. perfoliata (Hough-Goldstein et al. 2012). Consequently, this indicates that releasing $R$. latipes should be conducted continuously, primarily using mass-reared weevils. In terms of the releasing number of weevils, 200 weevils are typically released in a single release (Hough-Goldstein et al. 2015), although it is difficult to standardize the number of biocontrol agents per area because the plant and insect population might change by time. In addition, $P$. perfoliata populations have a patchy distribution in the landscape 
and often spreads into hard-to-access areas. The need for multiple weevil releases over time into a patchy, inaccessible invaded landscape makes the release of $R$. latipes challenging with the current hand-release method. Therefore, spatially-targeting and precision release of $R$. latipes could be a solution for more effective biocontrol of $P$. perfoliata on a landscape scale.

Aerial deployment of biocontrol agents has a great advantage in large-scale or site-specific pest management. Park et al. (2018) developed an aerial-release system for biocontrol agents of P. perfoliata, consisting of a pod that housed R. latipes, a pod dispenser, and UAS. Although the aerial-release system performed successfully, there were three drawbacks that needed to be developed and improved upon. First, the primary materials used for making the pods were cardboard for the frame, clay for the end caps, and plastic straws for housing $R$. latipes. Cardboard and clay can be degraded in the field, but plastic straws take up to 450 years to decompose, resulting in environmental contamination (Kreiger et al. 2013). Because the aim of the aerial release system is to control $P$. perfoliata in hard-to-access area, the pod should be biodegradable. Second, loading $R$. latipes into the pod was time consuming and required unreasonable precision. The straws used in Park et al. (2018) were $5 \mathrm{~mm}$ in diameter and $R$. latipes needed to be loaded one by one into the pod. Third, to release $R$. latipes from the pod after aerial deployment by UAS, the end cap made of clay had to be broken by ground impact. Because P. perfoliata generally makes a thick canopy in a patch, the necessary hard impact required may not occur in many sites. Therefore, the aerial release system for $R$. latipes needed to be modified and improved for successful spatially-targeted pest management.

This study was conducted to improve the aerial release system for spatially-targeted management of $P$. perfoliata using $R$. latipes (Fig.1). The objectives of this study were to develop a biodegradable pod for delivery of R. latipes (a.k.a. bug pod), to test the effects of the bug pod material on R. latipes, and to determine the ability of drones to identify populations of $P$. perfoliata to target for aerial releases. 


\section{Materials and Methods}

Study insect. $R$. latipes used in the study were collected in Waynesburg, Pennsylvania and were maintained in a rearing chamber in the Entomology Laboratory at West Virginia University, Morgantown, WV. The rearing chamber was kept as $16 \mathrm{~L}: 8 \mathrm{D}$ photoperiod regime under $23^{\circ} \mathrm{C}$ and $40-60$ $\%$ R.H. To feed R. latipes, P. perfoliata was grown on the moist bed in the greenhouse under $24^{\circ} \mathrm{C}$ and 70-80 \% R.H. Persicaria perfoliata achenes were collected directly from the soil under P. perfoliata patches and achenes were cold-moist stratified in a seedling tray with a wet potting soil mix (Pro-Mix BX; Premier Horticulture, Quebec, Canada) at $6.6^{\circ} \mathrm{C}$ from November 2018 through March 2019. After stratification, the tray was moved to a greenhouse growing room to germinate the seed. Germinants (cotyledon stage) were transplanted and grown under the same greenhouse conditions in round pots (15 cm by $14.5 \mathrm{~cm}$ ), with two or three plants per pot. These plants were maintained to keep $R$. latipes fed until they senesced in October. The stems were cut to increase branching and capitula material.

Study site. Experiments for aerial release of bug pod and detection of $P$. perfoliata were conducted on privately-owned land in Waynesburg, PA $\left(39^{\circ} 55^{\prime} 3.88^{\prime \prime} \mathrm{N}, 80^{\circ} 2^{\prime} 18.82^{\prime \prime} \mathrm{W}\right)$. The site was dominated by P. perfoliata, and Japanese stiltgrass [Microstegium vimineum (Trin.) A. Camus] was commonly observed at the site. The $P$. perfoliata patches were located in a relatively open, harvested area within surrounding woodland. Persicaria perfoliata was first observed in the area in the mid-1990s. Chemical control with a broad-spectrum herbicide (Roundup $\left.{ }^{\circledR}\right)$ was applied on the $P$. perfoliata once in 2010, and 3,000 R. latipes were released once in 2018 at the site. Both treatment methods have not been successful because large numbers of $P$. perfoliata patches remained.

Development of bug pod design. The design goals of the bug pod were: (1) easy loading of $R$. latipes, (2) easy escape of $R$. latipes from the bug pod after aerial release, and (3) environmentallyfriendly. The design of the bug pod was drawn by a 3-D designing tool (Solidworks ${ }^{\circledR}$; Dassault Systems, Vélizy-Villacoublay, France) (Fig. 2). For the precise design of the bug pod, the average width and length 
of 88 R. latipes adults were estimated using a digital microscope (AM7915MZT Dino-Lite Edge; AnMo Electronics Corp., Taipei, Taiwan). Based upon the width and length of $R$. latipes (Fig. 3), the size and design of the bug pod was determined. The bug pod was printed by using a 3D printer (Ultimaker 3 Extended; Ultimaker B.V., Cambridge, MA). Polyvinyl alcohol (PVA) filament (Ultimaker Natural PVA Filament; Ultimaker B.V., Cambridge, MA) was used for printing the bug pod. This filament was originally developed as a supporting material in fabrication of complex structures in 3-D printing. In this study, we used the filament as a main printing material to utilize its unique property of being soluble in water and biodegradable. The system for loading $R$. latipes into the bug pod was selected based upon the shape, size, and weight of the bug pod. Considering that a vacuum aspirator has been used for collecting small mites and insects in entomological studies (Singer 1964), a hand-held vacuum (Heavy Duty Handheld DC Vac/Aspirator; BioQuip Inc., Rancho Dominguez, CA) was selected as a tool for loading $R$. latipes into the bug pod quickly and safely.

Effect of PVA on R. latipes. Polyvinyl alcohol (PVA) is a synthetic polymer that is widely used in industrial, commercial, medical and food applications because of its biodegradability and biocompatibility (DeMerlis and Schneker 2003, Baker et al. 2013, Marin et al. 2014). This polymer can be easily degraded with water contact (e.g., rain, morning dew, and high humidity) and numerous studies reported that microorganisms with oxidases/hydrolases can degrade the PVA (Kawai 1999, Kim et al. 2003, Nogi et al. 2014, Ohtsubo et al. 2015). The safety of PVA was proven in toxicity studies with mammalians including rats and rabbits (DeMerlis and Schneker 2003), but there is a chance that PVA can negatively affect $R$. latipes. Therefore, a study was conducted to test the effect of PVA on the feeding ability and mortality of $R$. latipes. This study was replicated 20 times with a control and treatment: $R$. latipes that were kept in a 50 x $20 \mathrm{~mm}$ Petri dish with filter paper dipped in deionized water (control) and R. latipes that were kept in the Petri dish with filter paper dipped in 3\% PVA-dissolved solution (treatment) which is the optimum concentration allowing the solution to be absorbed into the filter paper (Patton and Robinson, 1975). In each replication, four R. latipes were randomly selected from the colony 
and gently placed into a Petri dish. After a 24-h exposure period, R. latipes were transferred to a clean Petri dish with a P. perfoliata leaf and a wet dental wick. Each P. perfoliata leaf was scanned (Brother DCP-7065DN; Brother Industries, Ltd., Nagoya, Aichi, Japan) before and after feeding to measure daily feeding amount. To quantify the amount of leaf consumed, an image analysis was performed to measure changes in the leaf area by using Adobe Photoshop CS4 (Adobe Inc., San Jose, CA). The mortality and feeding amount of $R$. latipes was monitored daily for a week under a $16 \mathrm{~L}: 8 \mathrm{D}$ photoperiod regime and under $23.7 \pm 0.01^{\circ} \mathrm{C}$ and $48.0 \pm 0.05$ R.H. Two separate trials were made to test the null hypothesis of no difference between control and treatment, repeated measures ANOVA was performed on collected data using JMP (SAS 2015) and SAS (SAS 2002) software at $\alpha=0.05$.

Effects of aerial release on R. latipes. Park et al. (2018) showed that the aerial release of bug pods at the altitude with $<30 \mathrm{~m}$ above the ground did not affect feeding ability and mortality of $R$. latipes. However, post aerial deployment of bug pods was not monitored in their study. In this study, we conducted a field test to measure the escaping ability of $R$. latipes from the bug pod after aerial deployment. A total of 120 R. latipes were randomly selected from the colony and starved for $24 \mathrm{~h}$ in a Petri dish (150 $\mathrm{mm}$ in diameter and $20 \mathrm{~mm}$ in height) before loading them into six bug pods (20 R. latipes per pod) to increase their motivation to chew their way out of the pod. All R. latipes were loaded by using the hand-held vacuum loader. Then a piece of $P$. perfoliata leaf was attached to the lid with a 3-mm hole to keep the $R$. latipes inside but to let them chew out after aerial release. The deployment date was chosen when three consecutive days without rain were forecasted. A bug pod was loaded on a dispenser (FliFli AirDrop Release and Drop Device; Arbity, Incheon, Republic of Korea), then the dispenser was attached to a drone (DJI Phantom 3 Advanced; SZ DJI Technology Co., Ltd., Shenzhen, China). The experiment was conducted on September 2019. According to Park et al. (2019), the bug pods were deployed aerially at $15-\mathrm{m}$ above the ground onto a $P$. perfoliata patch one at a time. Aerially deployed bug pods were recovered and placed on $P$. perfoliata patches to monitor escaping $R$. latipes by using time-lapse cameras (BrinnoTLC200Pro; Brinno, Taipei City 11493, Taiwan). We recovered bug pods and cameras three days 
later to count $R$. latipes that escaped from the bug pods. Any $R$. latipes remaining in the bug pods were counted to calculate the rate of successful escape.

Determination of aerial release sites. For spatially-targeted aerial release of $R$. latipes, we utilized two criteria to detect $P$. perfoliata patches from the aerial photos taken by UAS: (1) the equilateral triangular shape without lobes or indentations of $P$. perfoliata leaves on stem with nodes and (2) the distributional pattern of $P$. perfoliata forming a large monoculture. Although there are several congeners in North America, $P$. perfoliata leaves are readily identifiable by their triangular leaves. Prior to flying the drone at the site, a ground-truth was performed to mark the centroid of each plot. The aerial images were taken vertically from the centroid points at 15 different altitudes $(5,10,15,20,25,30,35$, $40,45,50,60,70,80,90$, and $100 \mathrm{~m}$ above the ground). Each of 15 images were collected from 13 plots (i.e. replications) and examined by using Photoshop to determine the detectability of $P$. perforliata by aerial imagery.

\section{Results}

Development of bug pod design. We developed a cylindrical-shaped bug pod with a top lid having 1-mm holes (smaller than R. latipes, which are $1.23 \pm 0.009 \mathrm{~mm}$ in width and $2.04 \pm 0.036 \mathrm{~mm}$ in length) (Fig. 4A) and a bottom lid with one 3-mm hole from which the R. latipes escape after release (Fig. 4B). The whole parts were fully fabricated using PVA filament. Due to failure to print the top of the lid with precise $1-\mathrm{mm}$ pinholes, we used a $0.8-\mathrm{mm}$ pin to make pinholes, allowing airflow for the vacuum loader when loading $R$. latipes and ventilating to keep $R$. latipes alive inside the bug pod (Fig. 4A). The thickness of the wall of the bug pod was $1 \mathrm{~mm}$ considering the balance between sturdiness and readiness to dissolve with water contact. The bug pod tightly fits in the suction pipe of the hand-held vacuum allowing the air flow focused to the 3-mm hole (Fig. 4C) 
Effect of PVA on R. latipes. The average feeding amount of a single $R$. latipes per day was 0.106 $\pm 0.005 \mathrm{~cm}^{2}$ for control and $0.104 \pm 0.005 \mathrm{~cm}^{2}$ for treatment in trial 1 , and $0.113 \pm 0.006 \mathrm{~cm}^{2}$ for control and $0.093 \pm 0.005 \mathrm{~cm}^{2}$ for treatment (PVA exposure) in trial 2 (Table 1). Although average feeding amount for both groups decreased gradually during the experiment (63.09\% for control and $64.21 \%$ for treatment in trial 1 and $58.59 \%$ for control and $68.79 \%$ for treatment in trial 2), we found no significant differences (Trial 1: $F=1.28 ; d . f .=6,98.8 ; P=0.275)($ Trial $2: F=1.54 ; d . f=6,101 ; P=0.174)($ Trial 1 $\& 2: F=0.94 ; d . f .=6,214 ; P=0.468)$ in feeding ability between control and treatment. There was no mortality in the controls, and only one and two deaths in the PVA treatments in trial 1 and 2, respectively (Table 1).

Determination of aerial release sites: The loading time for 20 R. latipes into each bug pod took less than a minute $(\mathrm{n}=6)$. There was no mortality or body damage from loading $R$. latipes by using the hand-held vacuum. According to the footage of time-lapse cameras for three days after the aerial deployment, we found that $98.3 \%(\mathrm{n}=118)$ of $R$. latipes could chew out and escape successfully from the bug pod within a day. In the recovered bug pods, two $R$. latipes were still remaining (one of which was alive, and the other was deceased) three days after aerial release. Aerial images were taken at 15 different altitudes to determine the detectability of $P$. perfoliata from other plants in the landscape (Fig. 5; $\mathrm{n}=13$ ). At the 5, 10, and $15 \mathrm{~m}$ above the ground, $P$. perfoliata was clearly detectable from the images. Detection of $P$. perfoliata on images taken at $20 \mathrm{~m}$ above the ground was successful $46 \%$ of the time, and all of images taken at higher altitudes were too blurred to detect $P$. perfoliata (Fig. 6). These results suggest that $P$. perfoliata is clearly detectable from aerial photos taken at $15 \mathrm{~m}$ or lower.

\section{Discussion}

Utilization of aircraft releasing natural enemies was first suggested by Herren et al. (1987). Since then, there have been several aerial-release systems using manned or unmanned aircrafts, including the release of sterile insects for areawide management (Tan and Tan 2013, Rosenthal 2017, M3 Consulting 
Group 2018), and biocontrol of European corn borer (Carroll et al. 2008). Recent advances in small UAS have created new opportunities to reduce application costs and increase coverage of areas compared to manual distribution (Filho et al. 2020). The UAS equipped with an aerial system we developed in this study presented the potential use of UAS for precision release of biocontrol agent to target weed patches. The bug pod we developed possesses three advantages over the one developed by Park et al. (2018). There was less labor involved in making the new bug pod. The former bug pod required multiple steps of cutting, gluing, casting, and delicate handling to complete. The new bug pod was designed for 3-D printing, and this can be easily reformed or resized with 3-D designing tool. With the 3-D printer used in this study, the bug pod could be printed approximately in $3 \mathrm{hrs}$ with an average weight of $6.0 \mathrm{~g}(\mathrm{n}=10)$. The total PVA mass used for printing a single bug pod cost approximately $\$ 1.23$, which is low-cost. There is also no additional clean up or environmental cost because the bug pod is biodegradable. Moreover, $R$. latipes was loaded quickly and easily into the bug pod by using the insect vacuum loader. Although the bug pod is fully water soluble, we observed in the field that the bug pod in high humidity became slimy before it fully liquified, which could increase the mortality of $R$. latipes. Therefore, when $R$. latipes is released with the bug pod, at least one dry day would be needed for the successful release of $R$. latipes as this study showed that most of R. latipes escaped from bug pod within $24 \mathrm{~h}$.

Once invasive plants become established, suppression and elimination of them is not easily achieved because of their ability to outcompete some native plants, their high reproductive potential, and their lack of natural enemies in their invaded range (Brook 1996, Hough-Goldstein et al. 2015). Physical and chemical control may reduce the invasive plant populations immediately, in the short-term. Reemergence after single treatment of invasive plants is likely due to propagules remaining in the soil as well as dispersal from other invaded areas. Longer-term control, thus, often requires frequent use of herbicides or more expansive removal of vegetation, which can increase negative impacts on non-target native plants. 
Mowing, cutting, and hand pulling, and application of broad-spectrum herbicides can immediately decrease P. perfoliata cover (Mountain 1989, Gover et al. 2008, Hough-Goldstein et al. 2015). However, these controls are most effective in the earlier stages of invasion, before seed set has occurred over multiple growing seasons. Otherwise, multiple applications of the treatment are needed. Moreover, removal of any invasive plants leaves the site open for re-invasion by P. perfoliata as well as invasion by different exotic plants (Lake 2011). The use of $R$. latipes as a classical biological control agent may enable a slower suppression of $P$. perfoliata, giving any existing or planted native species the upper-hand without additional disturbance and time to recover or grow (Hough-Goldstein et al. 2009, Hudson et al. 2017). R. latipes has been successfully integrated with herbicide applications and native plantings to control P. perfoliata and restore native plant communities (Cutting and Hough-Goldstein 2013, Lake et al. 2014).

The Federal Aviation Administration (FAA) set specific rules and regulations for the operation of small UAS in the National Airspace System (NAS). Title 14 of the Code of Federal Regulations (14 CFR) Part 107 specifically addresses not only the classification and certification of UAS but also operational limitations of UAS flights (FAA 2016). The 14 CFR states that a small UAS should be operated in cautious manner and cannot drop an object creating undue hazard to persons or property. The UAS system developed in this study drops a relatively light-weight bug pod $(6.0 \mathrm{~g})$ and operates in the landscape where humans may not have easy access. So, the possibility of harming persons or property is negligible. Also, the FAA regulates the maximum altitudes for flying UAS: $400 \mathrm{ft}$ or $122 \mathrm{~m}$. The operation of the UAS we developed is performed at $15 \mathrm{~m}$ above the ground for aerial deployment and below $20 \mathrm{~m}$ above the ground for detection of P. perfoliata. This falls well-below the maximum allowable altitude for UAS. As the UAS has to be flown over the hard-to-access area, the remote pilot may lose the visual line of sight because of the hilly landscape or high tree canopies. The 14 CFR addresses that the remote pilot in command and person manipulating the controls must maintain the visual line of sight on UAS at all times during flight. This can be resolved by other rules such as the use of visual observers in 
the field or acquisition of for a Certificate of Waiver $(\mathrm{CoW})$ prior to field operations. In the case of CoW, the administrator confirms that the proposed operation can be safely conducted and, thus, certain provisions of Part 107 can be exempted for UAS operation under a CoW. Therefore, the UAS for aerial release of biocontrol agent is legally acceptable to be operated in the landscape based on the current FAA rules and regulations.

The results of our study demonstrated the potential of UAS for precision aerial release of $R$. latipes in hard-to-access areas with a patchy distribution of $P$. perfoliata. The bug pod developed in the study was easy to create, easy to load, and fully fabricated with environmentally-friendly material with no negative effects on $R$. latipes mortality and feeding ability. Our study also showed that patchy populations of $P$. perfoliata for targeted aerial release of $R$. latipes could be successfully identified with UAS flown below $15 \mathrm{~m}$ above the ground. These results indicate that aerial detection of $P$. perfoliata and deployment of $R$. latipes for biological control in hard-to-access areas can be accomplished using a rotary-wing UAS. Future studies should be directed at long-term monitoring of $R$. latipes and estimation of the economic cost for the aerial release system.

\section{Literature Cited}

Antmann, A., S. Troufflard, and P. Armengaud. 2008. The effect of potassium nutrition on pest and disease resistance in plants. Physiol. Plant. 133: 682-691.

Baker, M. I., S. P. Walsh, Z. Schwartz, and B. D. Boyan. 2012. A review of polyvinyl alcohol and its uses in cartilage and orthopedic applications. J. Biomed. Mater. Res. - Part B Appl. Biomater. 100 B: $1451-1457$.

Carroll, M. W., J. A. Glaser, R. L. Hellmich, T. E. Hunt, T. W. Sappington, D. Calvin, K. Copenhaver, and J. Fridgen, 2008. Use of spectral vegetation indices derived from airborne hyperspectral imagery for detection of European corn borer infestation in Iowa corn plots. J. Econ. Entomol. 101: 1614-1623. 
Cheah, C. A. S.-J., and D. R. Ellis. 2019. Spread of mile-a-minute vine, Persicaria Perfoliata L. (Polygonaceae) to Connecticut islands in Long Island sound. Rhodora 121: 219.

Colpetzer, K., J. Hough-Goldstein, K. R. Harkins, and M. T. Smith. 2004a. Feeding and oviposition behavior of Rhinoncomimus latipes Korotyaev (Coleoptera: Curculionidae) and its predicted effectiveness as a biological control agent for Polygonum perfoliatum L. (Polygonales: Polygonaceae). Environ. Entomol. 33: 990-996.

Colpetzer, K., J. Hough-Goldstein, J. Ding, and W. Fu. 2004b. Host specificity of the Asian weevil, Rhinoncomimus latipes Korotyaev (Coleoptera: Curculionidae), a potential biological control agent of mile-a-minute weed, Polygonum perfoliatum L. (Polygonales: Polygonaceae). Biol. Contr. 30: 511-522.

Cusick, A. W., and M. Ortt. 1987. Polygonum perfoliatum L. (Polygonaceae): a significant new weed in the Mississippi drainage. SIDA 12: 246-249.

Cutting, K. J., and J. Hough-Goldstein. 2013. Integration of biological control and native seeding to restore invaded plant communities. Restor. Ecol. 21: 648-655.

DeMerlis C., and Schoneker D. R. 2003. Review of the oral toxicity of polyvinyl alcohol (PVA). Food Chem. Toxicol. 41: 319-326.

Ding, J., W. Fu, R. Reardon, Y. Wu, and G. Zhang. 2004. Exploratory survey in China for potential insect biocontrol agents of mile-a-minute weed, Polygonum perfoliatum L., in Eastern USA. Biol. Contr. 30: 487-495.

EDDMapS, 2020. Early Detection \& Distribution Mapping System. The University of Georgia - Center for Invasive Species and Ecosystem Health. Available from https://www.eddmaps.org/distribution/viewmap.cfm?sub=3065 
Federal Aviation Administration. 2016. Advisory circular-sUAS Part 107-2. US Department of Transportation, Federal Aviation Administration. Washington, DC.

Fernández-Quintanilla, C., J. M. Peña, D. Andújar, J. Dorado, A. Ribeiro, and F. López-Granados. 2018. Is the current state of the art of weed monitoring suitable for site-specific weed management in arable crops? Weed Res. 58: 259-272.

Filho, F. H. I., W. B. Heldens, Z. Kong, and E. S. De Lange. 2020. Drones: Innovative technology for use in precision pest management. J. Econ. Entomol. 113: 1-25.

Fredericks J. G. III. 2001. A survey of insect herbivores associated with Polygonum perfoliatum L. (mile-a-minute weed) and comparisons of leaf damage and insect diversity between recently established and mature populations. M.S. thesis, University of Delaware, Newark, DE, USA.

Frye, M. J., E. C. Lake, and J. Hough-Goldstein. 2010. Field host-specificity of the mile-a-minute weevil, Rhinoncomimus latipes Korotyaev (Coleoptera: Curculionidae). Biol. Contr. 55: 234-240.

Gover, A., J. Johnson, K. Lloyd, and J. Sellmer. 2008. Invasive plant species management quick sheet 7, mile-a-minute (Polygonum perfoliatum) (available from https://plantscience.psu.edu/research/projects/vegetative-management/publications/state-parksinvasive-species-management-quicksheets/7.-mile-a-minute-polygonum-perfoliatum) (accessed on: ).

Herren, H. R., T. J. Bird, and D. J. Nadel. 1987. Technology for automated aerial release of natural enemies of the cassava mealybug and cassava green mite. Int. J. Trop. Insect Sci. 8: 883-885.

Hyatt, L. A., and S. Araki. 2006. Comparative population dynamics of an invading species in its native and novel ranges. Biol. Invasions. 8: 261-275. 
Hough-Goldstein, J., E. C. Lake, R. Reardon, and Y. Wu. 2015. Biology and biological control of mile-a-minute weed. Morgantown, WV: USDA Forest Service Forest Health Technology Enterprise Team, FHTET-2008-10.

Hough-Goldstein, J., E. Lake, and R. Reardon. 2012. Status of an ongoing biological control program for the invasive vine, Persicaria perfoliata in eastern North America. BioControl 57: 181-189.

Hough-Goldstein, J., M. A. Mayer, W. Hudson, G. Robbins, P. Morrison, and R. Reardon. 2009. Monitored releases of Rhinoncomimus latipes (Coleoptera: Curculionidae), a biological control agent of mile-a-minute weed (Persicaria perfoliata), 2004-2008. Biol. Control. 51: 450-457.

Hudson, W., G. Robbins, J. DeSio, C. Detweiler, R. Strubel, A. Lovero, J. Beetle, and M. Mayer. 2017. Rhinoncomimus latipes (Coleoptera: Curculionidae) as a biological control agent for milea-minute, Persicaria perfoliata in New Jersey. Annual Report. Phillip Alampi Beneficial Insect Laboratory, Division of Plant Industry, New Jersey.

Kawai, F. 1999. Sphingomonads involved in the biodegradation of xenobiotic polymers. J. Ind. Microbiol. Biotechnol. 23: 400-407.

Kim, B. C., C. K. Sohn, S. K. Lim, J. W. Lee, and W. Park. 2003. Degradation of polyvinyl alcohol by Sphingomonas sp. SA3 and its symbiote. J. Ind. Microbiol. Biotechnol. 30: 70-74.

Kreiger, M., G. C. Anzalone, M. L. Mulder, A. Glover, and J. M. Pearce. 2013. Distributed recycling of post-consumer plastic waste in rural areas. Mater. Res. Soc. Symp. Proc. 1492: 91-96.

Kumar, V., and A. Ditommaso. 2005. Mile-a-minute (Polygonum perfoliatum): an increasingly problematic invasive species. Weed Technol. 19: 1071-1077.

Lake, E. C., J. Hough-Goldstein, and V. D'Amico. 2014. Integrating management techniques to restore sites invaded by mile-a-minute weed, Persicaria perfoliata. Restor. Ecol. 22: 127-133. 
Lake, E. C. 2011. Biological control of mile-a-minute weed, Persicaria perfoliata, and integrating weed management techniques to restore invaded sites. Ph.D. Dissertation. University of Delaware, Newark, DE, USA.

M3 Consulting Group. 2018. Codling moth sterile insect release. Available from http://www.m3cg.us/sir/

Marin, E., J. Rojas, and Y. Ciro. 2014. A review of polyvinyl alcohol derivatives: Promising materials for pharmaceutical and biomedical applications. African J. Pharm. Pharmacol. 8: 674-684.

Miller, W. R., B. A. Connolly, and D. Cygan. 2018. A new record of invasive mile-a-minute vine Persicaria perfoliata (Polygonaceae) in New Hampshire. Rhodora 120: 179-180.

Moul, E. T. 1948. a dangerous weedy Polygonum in Pennsylvania. Rhodora 50: 64-66.

Mountain, W. L. 1989. Mile-a-minute (Polygonum perfoliatum L.) update- distribution, biology, and control suggestions. Reg. Hort. 15: 1976-1979.

Nguyen, H. D. D., and C. Nansen. 2018. Edge-biased distributions of insects. A review. Agron. Sustain. Devel. 38.

Nogi, Y., M. Yoshizumi, K. Hamana, M. Miyazaki, and K. Horikoshi. 2014. Povalibacter uvarum gen. nov., sp. nov., a polyvinyl-alcohol-degrading bacterium isolated from grapes. Int. J. Syst. Evol. Microbiol. 64: 2712-2717.

Ohtsubo, Y., Y. Nagata, M. Numata, K. Tsuchikane, A. Hosoyama, A. Yamazoe, M. Tsuda, N. Fujita, and F. Kawai. 2015. Complete genome sequence of polyvinyl alcohol-degrading strain Sphingopyxis sp. 113P3 (NBRC 111507). 3: 5-6.

Park, Y. L., S. Gururajan, H. Thistle, R. Chandran, and R. Reardon. 2018. Aerial release of Rhinoncomimus latipes (Coleoptera: Curculionidae) to control Persicaria perfoliata (Polygonaceae) using an unmanned aerial system. Pest Manag. Sci. 74: 141-148. 
Patton, T. F., and J. R. Robinson. 1975. Ocular evaluation of polyvinyl alcohol vehicle in rabbits. J. Pharm. Sci. 64: 1312-1316.

Price, D. L., J. Hough-Goldstein, and M. T. Smith. 2003. Biology, rearing, and preliminary evaluation of host range of two potential biological control agents for mile-a-minute weed, Polygonum perfoliatum L. Environ. Entomol. 32: 229-236.

Rasmussen, J., J. Nielsen, F. Garcia-Ruiz, S. Christensen, and J. C. Streibig. 2013. Potential uses of small unmanned aircraft systems (UAS) in weed research. Weed Res. 53: 242-248.

Rosenthal, G. 2017. PPQ explores the tantalizing promise of unmanned air- craft systems. USDA APHIS. Available from https://www.aphis.usda.gov/aphis/ourfocus/planthealth/ppq-programoverview/plant-protection-today/articles/unmanned-aircraft-systems

SAS Institute, 2015. JMP®, Version Pro 14.0, SAS Institute Inc., Cary, NC.

SAS Institute, 2002. The SAS system for Windows. Version 9.4. SAS Institute Inc., Cary, NC.

Sétamou, M., and D. W. Bartels. 2015. Living on the edges: Spatial niche occupation of Asian citrus psyllid, diaphorina citri Kuwayama (Hemiptera: Liviidae), in citrus groves. PLoS One. 10 (7): e0131917. doi: 10.1371/journal.pone.0131917.

Singer, G. 1964. A simple aspirator for collecting small arthropods directly into alcohol. Ann. Entomol. Soc. Am. 57: 796-798.

Smith, J. R., and J. Hough-Goldstein. 2014. Impact of herbivory on mile-a-minute weed (Persicaria perfoliata) seed production and viability. Biol. Contr. 76: 60-64.

Tan, L. T., and K. H. Tan. 2013. Alternative air vehicles for sterile insect technique aerial release. J. Appl. Entomol. 137: 126-141. 
Van Clef, M., and E. W. Stiles. 2001. Seed longevity in three pairs of native and non-native congeners: assessing invasive potential. Northeast. Nat. 8: 301-310.

Wu Y., Reardon R., and J. Ding. 2002. Mile-a-minute weed. In: Van Driesche, R., Lyon, S., Blossey, B., Hoddle, M., and Reardon, R. Biological control of invasive plants in the Eastern United States. USDA Forest Service Publication FHTHT-2002-04. 
Table 1. Average feeding area (mean \pm SEM) of R. latipes in control $(n=40)$ and PVA-exposed $(n=40)$ group. The unit of measurement was $\mathrm{cm} 2$. No significant differences found between control and PVA-exposed groups $(\mathrm{P}>0.05)$.

\begin{tabular}{|c|c|c|c|c|c|c|c|c|}
\hline Trial & Day 1 & Day 2 & Day 3 & Day 4 & Day 5 & Day 6 & Day 7 & Daily average \\
\hline \multicolumn{9}{|l|}{ Trial 1} \\
\hline Control & $0.164 \pm 0.021$ & $0.104 \pm 0.023$ & $0.126 \pm 0.029$ & $0.086 \pm 0.012$ & $0.108 \pm 0.023$ & $0.092 \pm 0.024$ & $0.061 \pm 0.017$ & $0.106 \pm 0.005$ \\
\hline PVA & $0.154 \pm 0.030$ & $0.107 \pm 0.019$ & $0.163 \pm 0.029$ & $0.113 \pm 0.015$ & $0.101 \pm 0.021$ & $0.095 \pm 0.014$ & $0.055 \pm 0.011$ & $0.104 \pm 0.005$ \\
\hline \multicolumn{9}{|l|}{ Trial 2} \\
\hline Control & $0.152 \pm 0.018$ & $0.129 \pm 0.026$ & $0.109 \pm 0.023$ & $0.102 \pm 0.017$ & $0.080 \pm 0.011$ & $0.096 \pm 0.019$ & $0.063 \pm 0.012$ & $0.113 \pm 0.006$ \\
\hline PVA & $0.143 \pm 0.022$ & $0.128 \pm 0.017$ & $0.104 \pm 0.011$ & $0.069 \pm 0.024$ & $0.085 \pm 0.015$ & $0.069 \pm 0.014$ & $0.044 \pm 0.007$ & $0.093 \pm 0.005$ \\
\hline
\end{tabular}



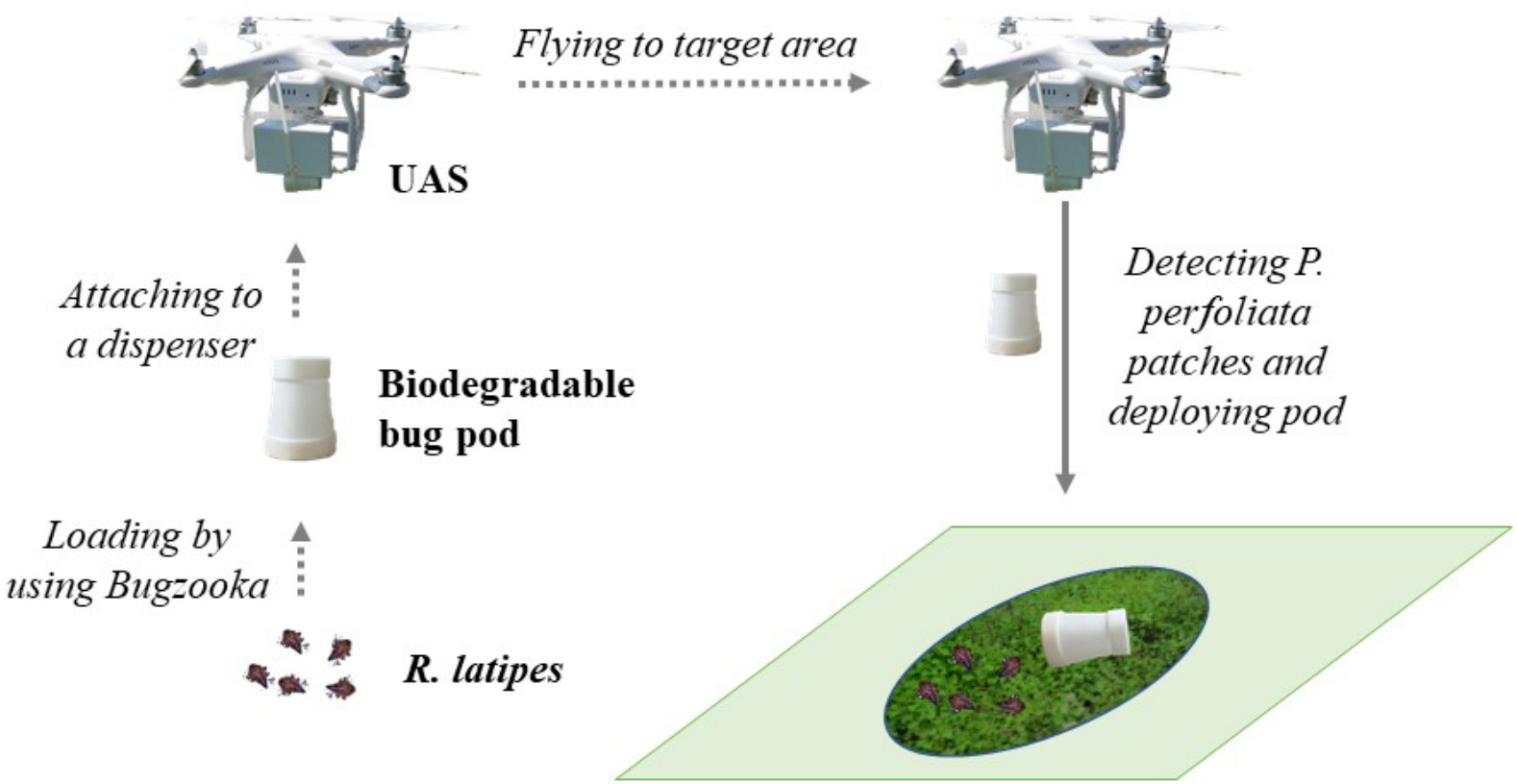

Fig. 1. Schematic diagram of aerial-release systems and an operational protocol with UAS. R. latipes adults will be loaded into a bug pod by using a vacuum. The pod is attached to a UAS dispense (Park et al. 2018). UAS are flown to detect $a$ P. perfoliata patch and deploy the bug pod over the $P$. perfoliata patch. 

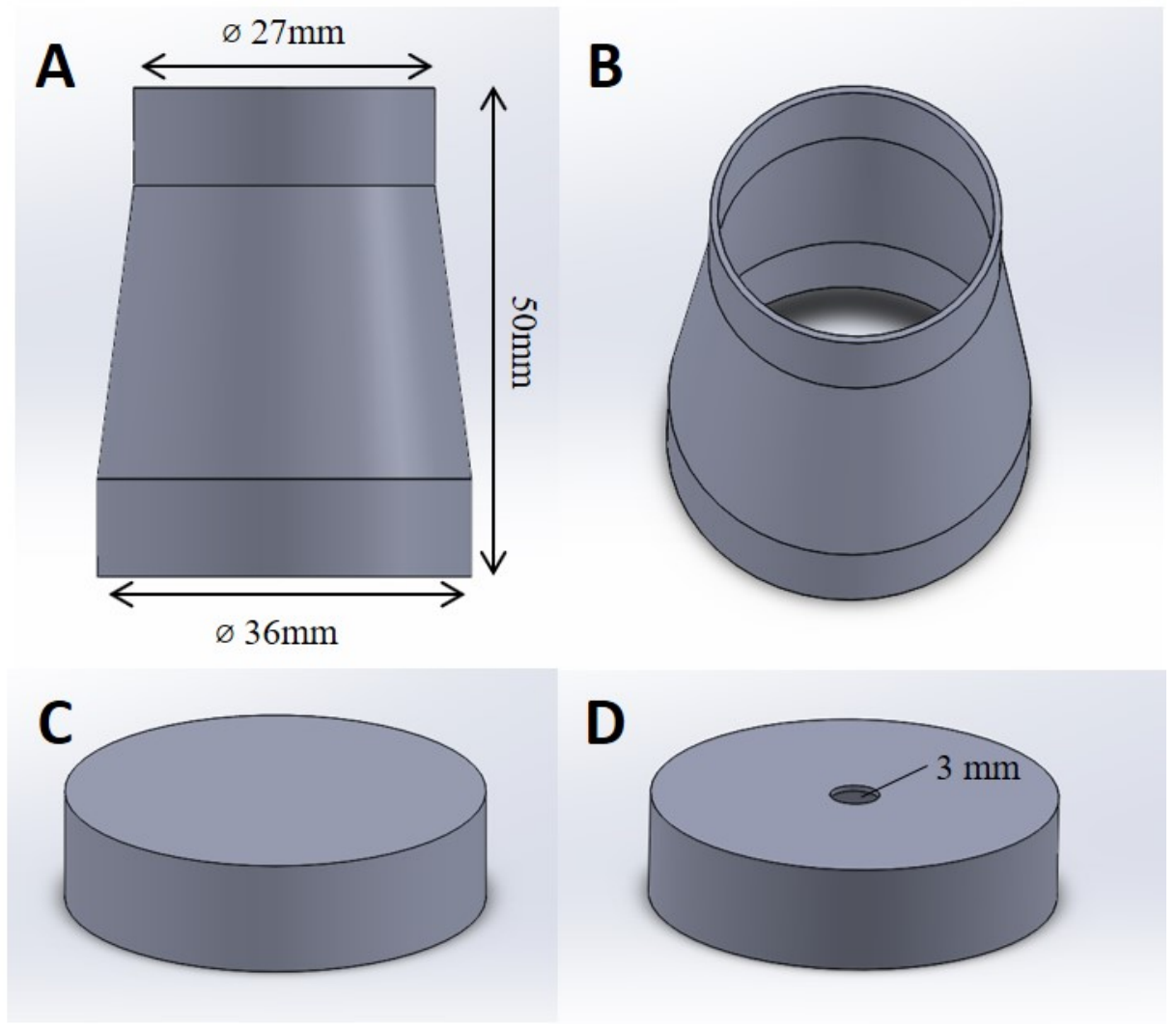

Fig. 2. Schematic design of the bug pod using Solidworks ${ }^{\circledR}$. A, side view; B, perspective view; C, bottom lid for loading the weevils; $\mathrm{D}$, top lid with a 3-mm hole for $R$. latipes to escape after aerial release. 


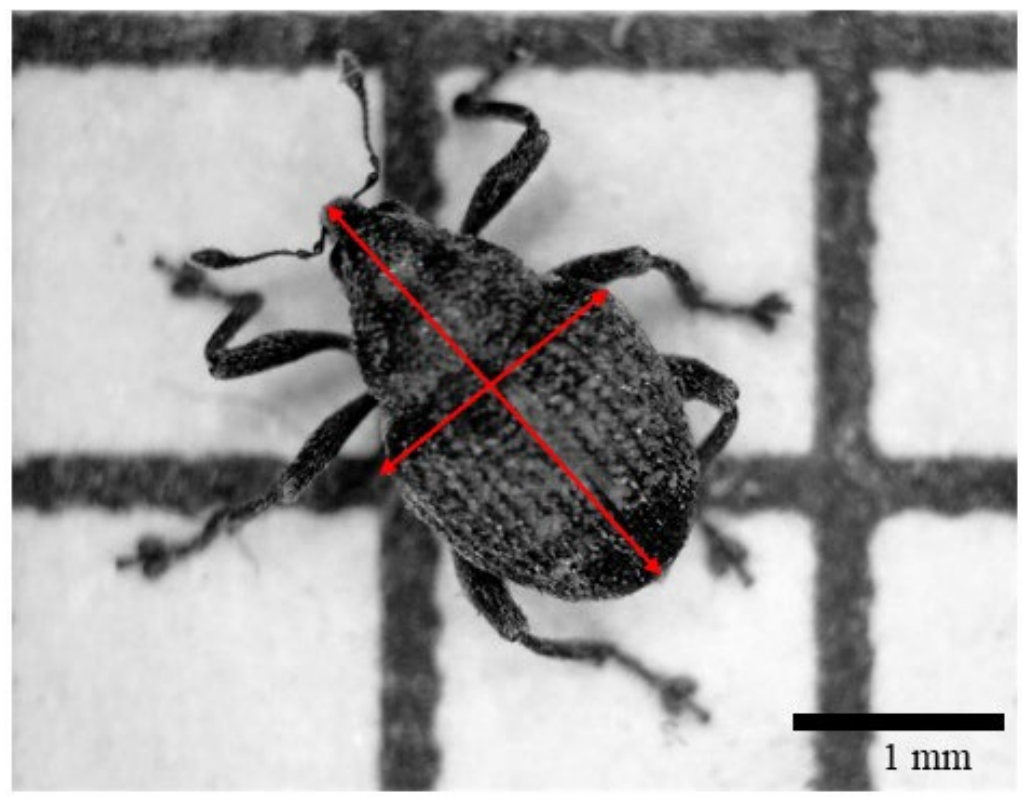

Fig. 3. Size estimation based on the width and length of $R$. latipes using a digital microscope to determine precise design of bug pod. 


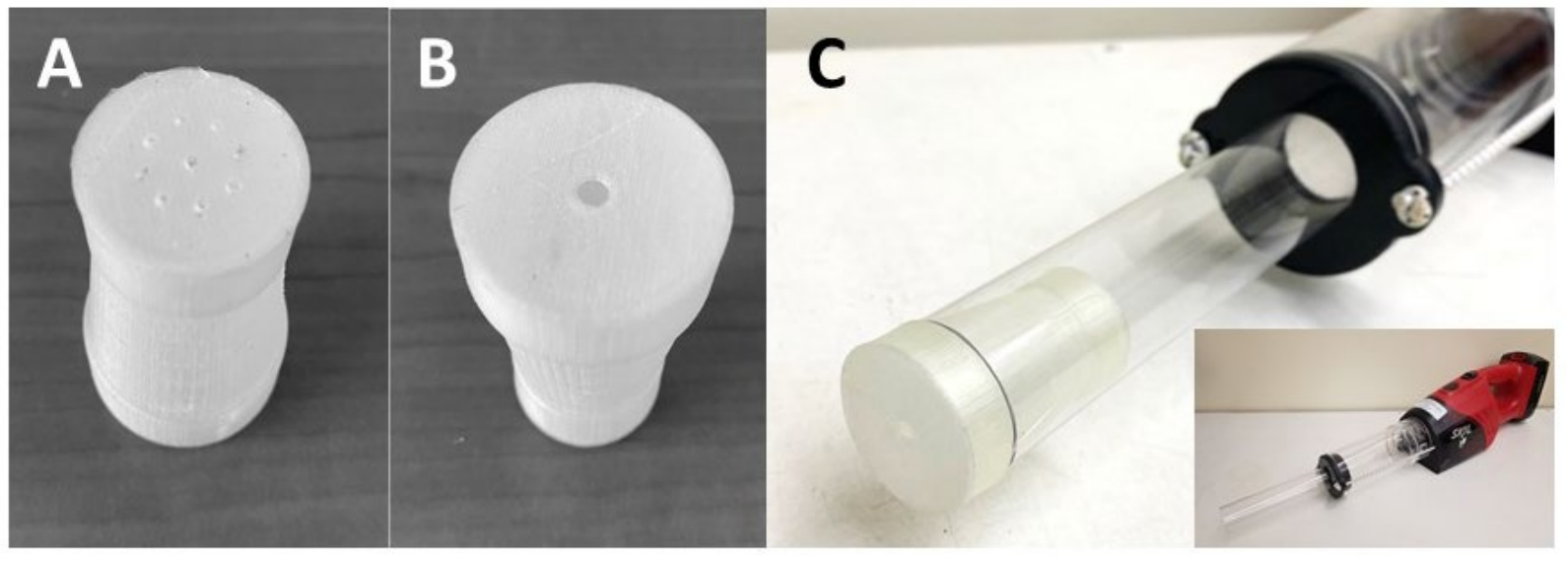

Fig. 4. Example bug pod printed by 3-D printer using PVA. A, view from the bottom of the bug pod with pin holes for ventilation; B, view from the top of the bug pod with an exit hole that is covered with a pieces of $P$. perfoliata leaf; $\mathrm{C}$, a vacuum to load $R$. latipes into the bug pod. 


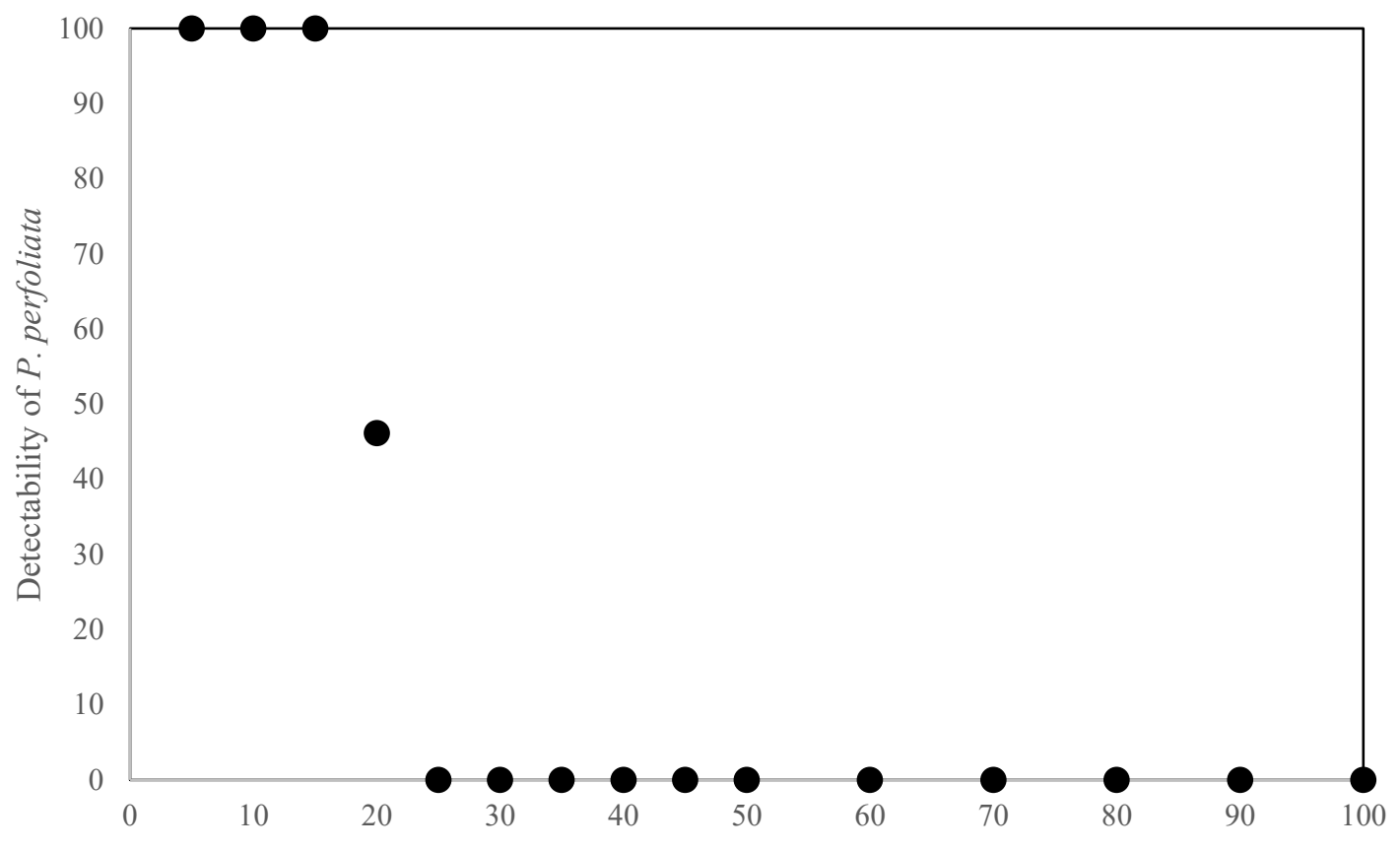

Flight altitude (m)

Fig. 5. Detectability of $P$. perfoliata by UAS flown at different altitudes $(n=13$ per flight altitude). 

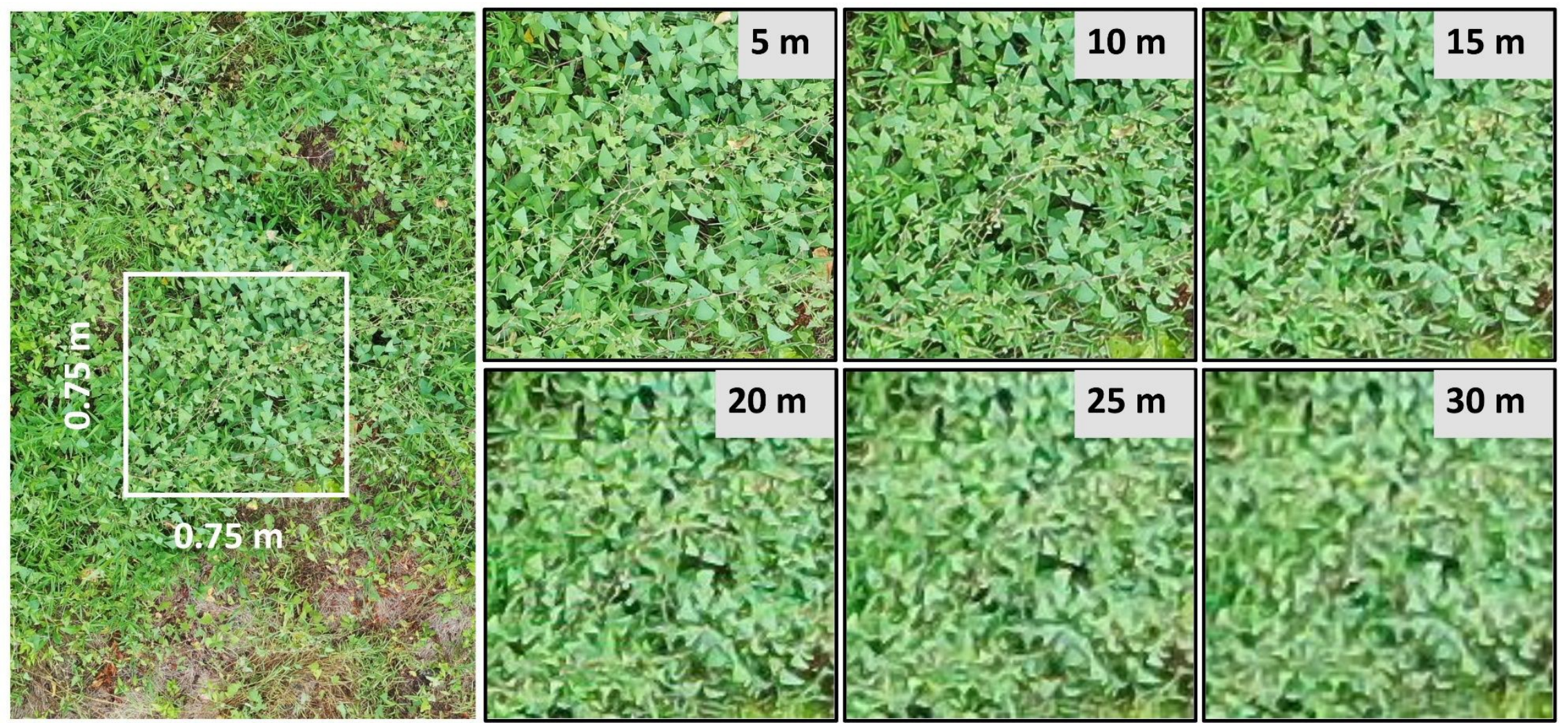

Fig. 6. Detectability of $P$. perfoliata patches (left) based on aerial images acquired from UAS at different flight altitudes. Note that $P$. perfoliata could not be detected the image taken by UAS at $>25 \mathrm{~m}$ above the ground. 


\title{
Chapter 3: Persicaria perfoliata's (Polygonaceae; Mile-a-minute weed) dominated plant communities: a description of species abundances, richness, diversity, and plant composition
}

\begin{abstract}
Persicaria perfoliata (L.) H. Gross (Polygonaceae) (mile-a-minute weed) is an annual invasive vine introduced from Asia to the northeastern U.S. in the 1930s. This weed invades disturbed areas and reforestation sites, forming dense, monocultural patches that may inhibit forest regeneration. Currently, the species composition of $P$. perfoliata's invaded areas, including any potentially coexisting and competing species, is understudied. This study was conducted to compare the species composition of $P$. perfoliata-dominated (dominated) patches with adjacent patches where $P$. perfoliata is not dominant (notdominated) within an environmentally homogeneous site infested with $P$. perfoliata. We established plots in two invaded sites in southwestern Pennsylvania, sampled existing plant species, and estimated species percent cover from each site. To better evaluate the species existing in the $P$. perfoliata infested sites, we identified all vascular plant species and compared the species composition of the P. perfoliatadominated patches with the non-dominated patches using multivariate analyses. The relative importance of all vascular plant species (combined cover and frequency values), richness, diversity, and evenness were determined for each plot type. Significant differences in species composition in the two plot types were determined using nonmetric multidimensional scaling and a multi-response permutation procedure. Indicator species within the plot types were also calculated. There were a total of 36 and 26 species from the JS and RV sites, respectively. Species richness and diversity were lower in the P. perfoliata dominated plots than the nondominated plots, but only significant in the JS site. In addition, an exotic invader, Microstegium vimineum, and native weed, Ambrosia artemisiifolia, were the most important species in the nondominant plots in JS and RV sites, respectively. These results indicate that understanding potentially coexisting native and exotic species within the invaded landscape with a
\end{abstract}


dominant invasive plant targeted for removal will better inform comprehensive weed management for restoration of invaded sites.

Keywords: Persicaria perfoliata, Biological invasion, Species composition, Multivariate analysis, Restoration 
Biological invasions of exotic plants negatively affect the diversity and abundance of native plants (Tilman 1999, Hejda et al. 2009, Flory and Clay 2010a), vertebrates (Horncastle et al. 2005, Nelson et al. 2017), invertebrates (Graves and Shapiro 2003, Moroń et al. 2009), ecological communities (Richardson et al. 1989, Kohli et al. 2004), and ecosystem processes (Gordon 1998, Standish et al. 2004, Richardson et al. 2007). Consequently, such impacts may result in excessive management costs (Mason et al. 2007). Wilcove et al. (1998) estimated that $57 \%$ of the threatened or endangered plants in the United States are imperiled by alien plants, and Pimentel et al. (2001) estimated that the United States spends approximately 34 billion dollars per year to control weeds of croplands and pastures and another 145 million per year to control exotic invasive plants in natural areas. While a rich literature base exists on certain individual invasive exotic plant species, the scientific community is far from understanding their role within a community or ecosystem context.

Understanding how invasive plants interact with associated native plants, especially aggressive early-successional species and other exotic plants, may help us predict the recovery trajectory after the removal of the target invasive plant. It is often assumed that invasive plants are more competitive than native species, but there is evidence that some invasive plants may not be all that competitive. It is important to differentiate between direct species competition and early opportunistic colonization that takes place immediately after a disturbance. Vilá and Weiner (2004) conducted a meta-analysis on the available literature on competition and found that there was a $47 \%$ reduction in biomass of native species caused by direct competition from exotic species and an $18 \%$ reduction of exotic species caused by direct competition from a native species. They note, however, that the studies may be biased towards positive outcomes and unusually weak native competitors. In addition, the patches with one or more dominant invasive species in severely invaded areas may depend on how multiple invasive species interact with each other in addition to how they interact with any remaining native species over time (Kuebbing et al. 2013). For example, the native Robinia pseudoacacia L. seedlings facilitate the growth of Ailanthus 
altissima (Mill.) Swingle seedlings likely via nitrogen fixation and at later stages of growth interspecific competition results in A. altissima being the stronger competitor. (Nilsen et al. 2018).

Highly invaded sites that have been infested by a dominant exotic plant for several years often are characterized by a mosaic of patches of various sizes and abundances of that dominant invasive plant (Kartzinel et al. 2015, Petrovskaya et al. 2017). If this patchy mosaic occurs in a physiographicallyhomogeneous environment, one may hypothesize that patches lacking in the dominant invader include plant species that make local spread by the invader more difficult; these species could include native species, exotic species, or other exotic invaders. More importantly, these patches may serve as a refuge for less abundant native species and ensure their recovery after removal of the dominant invasive plant. Determining the species composition of patches with low abundance of a dominant invader adjacent to patches with a high abundance of the dominant invader may provide information about competitive species that could exclude the invader or coexist with the invader especially in response to the invaders' managed reduced dominance.

This study focuses on the invasive Persicaria perfoliata (L.) H. Gross (Polygonaceae) (mile-aminute weed). Persicaria perfoliata is an annual vine with characteristic triangular leaves, ocrea surrounding the stems, and small recurved prickles. This weed can grow up to $6 \mathrm{~m}$ in one growing season (Okay 1997) and forms various patch sizes and shapes. This plant has invaded at least 15 states of the northeastern and mid-Atlantic United States (Kumar and DiTommaso 2005, Hough-Goldstein et al. 2012, Hough-Goldstein et al. 2015, EDDMaps 2020). Although P. perfoliata is typically found along disturbed riparian areas in Asia (Hyatt and Akari 2006, Hough-Goldstein et al. 2015), in the U.S., it also invades disturbed areas (i.e., construction site, roadsides, and utility rights-of-ways) and recently harvested forests (Cusick and Ortt 1987, Wu et al. 2002, Hough-Goldstein et al. 2008, Hough-Goldstein et al. 2015). In its invaded region, it suppresses native flora, decreases plant diversity across landscapes, and is a nuisance to humans due to its sharp recurved prickles and the formation of impenetrable areas made up of multiple large and small patches (Oliver 1997, Hough-Goldstein et al. 2015). Its overtopping other plants and 
producing masses of intertwining foliage makes these areas appear as monocultures, though a closer look reveals the presence of other species. These infestations also leave a notable thatch of dead plant material each year that slowly decomposes but can be used to delineate the existence of previous year's patch locations as well as potentially estimate spread rates as patches possibly increase in size. Nonetheless, thousands of $P$. perfoliata seeds falling in summer and fall can be viable for up to six years in seed banks and may germinate under the previous year's plants with an average density of $200-500$ per $0.5 \mathrm{~m}^{2}$ (Hough-Goldstein et al. 2015), ensuring a self-perpetuating population. Thus, any control measures of $P$. perfoliata will likely require long-term monitoring and multiple years of removal or possible use of preemergent herbicides.

Our goal is to compare the species composition of $P$. perfoliata-dominated (dominated) patches to adjacent patches where $P$. perfoliata is not dominant (nondominated) within an environmentally homogeneous site that has been infested with $P$. perfoliata for at least five years. We hypothesize that dominated patches will have fewer native species but in the not-dominated patches, there will be one or more dominant native species or another dominant invasive plant. We also hypothesize that the nondominated patches will be more species-rich than the dominated patches, but they will be equally uneven. Information about these native and other exotic species will inform any management decisions about future removal of $P$. perfoliata, including biocontrol efforts. This information will enable land managers to plan for any need for active restoration involving the planting of native species or the likely spread of other exotic species in response to removing P. perfoliata.

\section{Materials and Methods}

Study area. The abundance of all vascular plants associated with infestations of $P$. perfoliata was determined at two open, previously forested, sites in southwestern PA. These privately owned sites were located near Jefferson (JS), PA in Greene county $\left(39^{\circ} 55^{\prime} 3.88^{\prime \prime} \mathrm{N}, 80^{\circ} 2^{\prime} 18.82^{\prime \prime W}\right)$ and near Rogersville (RV), PA in the same county $\left(39^{\circ} 53^{\prime} 12.09^{\prime \prime} \mathrm{N}, 80^{\circ} 17^{\prime} 1.61^{\prime \prime} \mathrm{W}\right)$ and were $848 \mathrm{~m}^{2}$ and $315 \mathrm{~m}^{2}$ from aerial mapping, respectively. In the JS site, chemical control with a broad-spectrum herbicide (Roundup®) was 
applied on the $P$. perfoliata once in 2010, but the application did not control $P$. perfoliata. Both sites have also had the mile-a-minute weevil, Rhinoncomimus latipes, released as a biocontrol once in 2015 and 2017 in RV site, and in 2018 for JS site, respectively, but with limited impact. At the time of the study, the open, relatively flat harvested areas were inundated with $P$. perfoliata. Our study focused only on the open invaded areas that shared the same topography and similar disturbance histories (aside from the JS herbicide application).

Vegetation sampling and data preparation. A $P$. perfoliata patch was defined as any area with $\geq$ $75 \%$ cover of $P$. perfoliate thatch from previous years. Patches were selected from three patch sizes using the remaining $P$. perfoliata thatch from previous years determined from aerial photography taken with a UAV (DJI Phantom 3 Advanced; SZ DJI Technology Co., Ltd., Shenzhen, China) and ground-truth. Within patches that were $<10 \mathrm{~m}^{2}$, one $1 \mathrm{~m}^{2}$ circular plot was fit for potential vegetation sampling. Two $1-\mathrm{m}^{2}$ plots were fit in patches $\geq 10 \mathrm{~m}^{2} \&<30 \mathrm{~m}^{2}$, and three $1-\mathrm{m}^{2}$ plots for $\geq 30 \mathrm{~m}^{2}$ (Fig. 1). A total of 10 plots were randomly selected from the total 26 potential plots in JS site and 28 potential plots in RV site, respectively. An additional 10 plots not dominated by $P$. perfoliata (e.g., adjacent but outside of the patch) were paired (within $5 \mathrm{~m}$ ) with these selected plots. The 20 plots at each of the two sites were sampled from late June to early August in 2019. Within each $1 \mathrm{~m}^{2}$ plot, four quarters were created (Fig. 2). Within each of the quarters, percent cover was visually estimated for each woody tree seedling (less than $1 \mathrm{~m}$ tall) rooted in the plot and every shrub, herbaceous, and vine species rooted or with vegetation hanging within the plot boundary (Huebner 2007). The cover of the four quarters was averaged and frequency (the number of quarters containing each species out of four) was determined for each species within each $1-\mathrm{m}^{2}$. The cover and frequency values were then averaged to formulate an importance value (IV) for each species and the IVs were relativized using the following formula:

$$
\text { Relative } I V_{i j}=\frac{I V_{i}}{M_{j}}
$$


The relative IV represents the extent of dominance of species $i$ in each sampled plot. $\operatorname{IV}_{i}$ is the importance value of the species $i$ in plot $\mathrm{j}$, and $\mathrm{M}_{\mathrm{j}}$ is the sum of the importance value of whole species in plot $\mathrm{j}$. Plants were identified to species when possible, otherwise to genus. Species nomenclature followed Rhoads and Block, (2000) and Gleason and Cronquist (1993), with final accepted names defined by the Integrated Taxonomic Information System (https://www.itis.gov/).

Data analyses. In order to separate site-effects, differences between dominated and nondominated plots were determined by evaluating each site separately as well as combining the two sites. In addition, data sets were organized such that $P$. perfoliata cover was included or excluded from the analyses but only the latter is presented. Plant species richness, diversity (Shannon-Weiner), and evenness were calculated using PC-ORD 7 (McCune and Mefford 2016)

Nonmetric multidimensional scaling (NMS) and Indicator Species Analysis (ISA) (PCord v 7, Kruskal 1964, McCune and Grace 2002) were used to evaluate plant composition between the dominated and nondominated plots both within site and with sites combined. The NMS analyses consisted of 500 real runs, 500 iterations, with random starting configuration, using a Sorensen (Bray-Curtis) distance measure (PC-ORD7; McCune and Mefford, 2016). To minimize the noise in the data with many zeros, Beals smoothing (Beals, 1984) was conducted before the analyses. Data were evaluated with and without the Beals smoothing, recognizing weaknesses associated with Beals smoothing in that it may produce reliable trends even from series of random numbers (McCune and Grace 2002, De Cáceres and Legendre 2008)

We used a multi-response permutation procedure (MRPP) with a Sorenson distance measure to compare the dominated and nondominated plots both within each site and with sites combined as well with and without P. perfoliata cover included but present only the latter (PC-ORD v. 7, McCune and Mefford, 2016). MRPP is a method providing a nonparametric multivariate test of differences between two or more groups, not requiring distributional assumptions (e.g. normality and homogeneity) (McCune and Grace 2002). 
Analysis of variance (ANOVA) was used to test for differences in species richness, diversity, and evenness between the dominated plots and nondominated plots. Data met normality and homogeneity assumptions. Multiple comparisons, including site interactions, were made with least-square means and a Tukey adjustment with $\alpha=0.05$ (SAS 2013) using SAS 9.4 software.

\section{Results}

Species composition. There were 36 and 26 species at the JS and RV sites, respectively, and 54 different species for the combined dataset and 8 species common between the sites (Appendix 1). At the JS site, Microstegium vimineum (Trin.) A. Camus, Persicaria longiseta (Bruijn) Kitag., Impatiens capensis Meerb., and Pilea pumila (L.) A. Graywere the most important species for both the dominated and nondominated plots (Table. 1). In the RV site, Celastrus orbiculatus Thunb., Ambrosia artemisiifolia L., Oxalis stricta L., and Acalypha rhomboidea Raf. were the most important species in the dominated plots, while $A$. artemisiifolia, $C$. orbiculatus, $O$. stricta, and $T$. pretense were the most important species in the nondominated plots (Table. 1). Of all 54 species, including $P$. perfoliata, at both sites, 45 species (83\%) were native to North America and 9 species (17\%) were non-native as defined by USDA PLANTS, Natural Resources Conservation Service.

NMS, MRPP, ISA results. The most stable NMS ordination for the Beals-smoothed combined data was a two-dimensional solution and had a final stress value of 5.9 and a final instability value of 0.0 after 500 iterations (Fig. 3). Although the original combined dataset without Beals smoothing had a final stress value of 4.7 with identical options, only a single-dimensional solution was recommended. The twodimensional ordination was dominated by plots from JS on the right, and plots from RV on the left showing less dissimilarity between dominated and nondominated plots (Fig. 3). The individual sites were evaluated separately with Beals smoothing, because e NMS ordination of the original non-smoothed data from each site was too unstable (final stress $>40$ ) with a one-dimensional solution. The most stable NMS ordination for JS and RV with Beals smoothed dataset was a three-dimensional solution for each site (JS: 
final strass $=8.1$, final instability $<0.000001 ; \mathrm{RV}$ : final stress $=7.2$, final instability $<0.000001)$ (Fig. 4), showing a separation between the dominated and nondominated plots within each site.

MRPP analysis indicated that plant composition results of the dominated and nondominated plots were statistically different, but with stronger differences between the sites than between the plot types (Table. 2). The indicator species analysis showed that a single species, Microstegium vinimeum (Japanese stiltgrass), was an indicator species of the JS site and seven species were detected as indicator species for RV site, with Celastrus orbiculatus being the most important. The plot types within JS did not have indicator species because they shared the same dominant species with similar abundances. Within the RV site, the nondominated plots had a native indicator species, A. artemisiifolia, whereas the dominated plots had C. orbiculatus as the indicator species (Table. 3 ).

Species richness, diversity, and evenness. Mean \pm S.E. of species richness and Shannon's Diversity Index were lower in dominated plots compared with nondominated plots in both sites but was only significantly different in JS, where $M$. vimineum was dominant (Fig. 3A and 3B). Evenness did not differ between dominated vs nondominated plots in either site (Fig. 3C). These results suggest that the dominance of $P$. perfoliata decreases native species richness and diversity of the dominated patches, but that abundant native species at the RV site may be keeping $P$. perfoliata from spreading. At the RV site, the native weedy species, $A$. artemisiifolia, dominates and may even help keep another invasive, $C$. orbiculatus, from becoming dominant. Celastrus orbiculatus appears to fair better with P. perfoliata being present and dominant than when A. artemisiifolia dominates (Table 1).

\section{Discussion}

There have been many studies addressing how invasive plants directly or indirectly reduce the diversity and abundance of native plant species (Hejda et al 2009, Molinari and D'antonio 2014,). Our study supports a decrease in species richness and diversity in P. perfoliata - dominated patches compared to nondominated patches in highly invaded sites that are physiographically homogeneous. The fact that $P$. 
perfoliata usually forms dense, monocultural patches indicates its dominance over available resources may prevent germination, survival, and growth of existing native species and other nonnative species. However, we found several coexisting native and exotic species in our study. Based on the rank of relative IV and ISA, Microstegium vimineum was a dominant species in both dominated and nondominated plots in JS site whereas the native Ambrosia artemisiifolia dominated the nondominant plots, even surpassing another invader (C. orbiculatus) in relative cover at the RV site. Microstegium vimineum and C. orbiculatus are common invasive species in the northeastern U.S. that may further impact ecosystem properties by changing soil properties including higher $\mathrm{pH}$ values, higher nitrification, and higher litter decomposition rates (Ehrenfeld and Scott 2001, Ehrenfeld 2003, Leicht-Young et al. 2009). Ambrosia artemissifolia and Oxalis stricta are native species to North America but are regarded as common weeds in multiple early successional habitats that decrease in abundance as succession proceeds (Bassett and Crompton 1975, Marble et al. 2013). The RV site could conceivably recover after removal of P. perfoliata without a need to plant additional native species or removal of other exotics, though it would be prudent to remove $C$. orbiculatus as well. In contrast, the JS site will clearly be dominated by $M$. vimineum and another exotic after removal of $P$. perfoliata, unless management also includes removal of M. vimineum and Persicaria longeseta. However, at both the RV and JS sites, there are a number of native species present that are posed to increase in abundance. This study highlights the importance of knowing the plant species composition of a site before applying any management regime.

Currently, management of $P$. perfoliata mainly relies on pre- and post-emergent herbicides and biological control (Mountain 1989, Gover et al. 2008, Hough-Goldstein et al. 2015). Physical and mechanical removal may be effective for small populations, though there is still a chance viable seeds in the seedbank will germinate later. It is well documented that removal or suppression of a dominant invasive weed can cause invasion of different invasive plants or dominance by coexisting exotic plants (Westman 1990, Erskine Ogden and Rejmánek 2005). However, the use of classical biological control agent, Rhinoncomimus latipes Korotyaev (Coleoptera: Curculionidae) may enable a longer recovery 
period with slow suppression of $P$. perfoliata, allowing existing or planted native plant species to recover or grow (Hough-Goldstein et al. 2009, Hudson et al. 2017). This host-specific biocontrol agent causes significant feeding damage to $P$. perfoliata and stem-boring larvae reduce its growth and reproductive potential (Colpetzer et al. 2004, Smith and Hough-Goldstein 2014). Although there were release records of $R$. latipes in both study sites, no subsequent study was yet conducted to estimate the effect of biological control on those sites. Because other dominant exotic and native species coexist in the invaded sites, a subsequent release of $R$. latipes should be considered in the context of integrated weed management.

Restoration of invaded natural ecosystems must take all species present at the site into account and not just any initial focal species being removed (Flory and Clay 2010b, Lake et al. 2014). Westman (1990) suggested the removal of invasive weed without a restoration plan of the native community can result in severe abiotic alteration causing further modifications of the site. The target weed of our study, P. perfoliata, is commonly found with the invasive grass, M. vimineum (Lake 2011), and our data support this at one site. Cutting and Hough-Goldstein (2013), and Lake et al (2014) found that the successful suppression of $P$. perfoliata without also removing $M$. vimineum can result in subsequent domination by M. vimineum and our data support this. In contrast, removal of P. perfoliata at the RV site could potentially result in the native $A$. artemisiifolia dominating, but with $C$. orbiculatus coexisting in the species mix. In both cases, the greater species richness of the nondominated plots is due to more native species being present, but with each in very low abundance. Increases in these native species is not likely to occur at the JS site, without the joint removal of M. vimineum, whereas, RV may see an increase in the less common native species after removing $P$. perfoliata as succession progresses. Succession dominated by native species may progress faster at the RV site if $C$. orbiculatus is also removed.

The results of our study suggest that the dominance $P$. perfoliata affects native plant communities negatively and that restoration after any $P$. perfoliata control efforts should be aware of the presence of other dominant exotic and native species. Microstegium vimineum, and A. artemisiifolia at the JS and RV 
sites, respectively, have a high potential for becoming a subsequent dominant species after successful weed management of $P$. perfoliata. These results suggest that understanding potentially coexisting native and exotic species within any infested landscape with a dominant invasive plant targeted for removal will help determine the likelihood of restoration success.

\section{Literature Cited}

Bassett, I. J. and C. W. Crompton. 1975. The biology of Canadian weeds. 11. Ambrosia artemisiifolia L. and A. psilostachya DC. Can. J. Plant Sci. 55: 463-376.

Beals, E. 1984. Bray-Curtis ordination: an effective strategy for analysis of multivariate ecological data. Adv. Ecol. Res. 14:1-55.

Colpetzer, K., J. Hough-Goldstein, K. R. Harkins, and M. T. Smith. 2004. Feeding and oviposition behavior of Rhinoncomimus latipes Korotyaev (Coleoptera: Curculionidae) and its predicted effectiveness as a biological control agent for Polygonum perfoliatum L. (Polygonales: Polygonaceae). Environ. Entomol. 33: 990-996.

Cusick, A. W., and M. Ortt. 1987. Polygonum perfoliatum L. (Polygonaceae): a significant new weed in the Mississippi drainage. SIDA 12: 246-249.

Cutting, K. J., and J. Hough-Goldstein. 2013. Integration of biological control and native seeding to restore invaded plant communities. Restor. Ecol. 21: 648-655.

De Cáceres, M., and P. Legendre. 2008. Beals smoothing revisited. Oecologia 156: 657-669.

EDDMapS, 2020. Early Detection \& Distribution Mapping System. The University of Georgia -Center for Invasive Species and Ecosystem Health.

https://www.eddmaps.org/distribution/viewmap.cfm?sub=3065 
Ehrenfeld, J. G. 2003. Effects of exotic plant invasions on soil nutrient cycling processes. Ecosystems. 6: $503-523$.

Ehrenfeld, J. G., and N. Scott. 2001. Invasive species and the soil: effects on organisms and ecosystem processes. Ecol. Appl. 11: 1259-1260.

Erskine Ogden, J. A., and M. Rejmánek. 2005. Recovery of native plant communities after the control of a dominant invasive plant species, Foeniculum vulgare: implications for management. Biol. Conserv. 125: $427-439$.

Flory, S. L., and K. Clay. 2010a. Non-native grass invasion suppresses forest succession. Oecologia 164: 1029-1038.

Flory, S. L., and K. Clay. 2010b. Non-native grass invasion alters native plant composition in experimental communities. Biol. Invasions. 12: 1285-1294.

Graves, S. D., and A. M. Shapiro. 2003. Exotics as host plants of the California butterfly fauna. Biol. Conserv. 110: 413-433.

Gordon, D. R. 1998. Effects of invasive, non-indigenous plant species on ecosystem processes: Lessons from Florida. Ecol. Appl. 8: 975-989.

Gover, A., J. Johnson, K. Lloyd, and J. Sellmer. 2008. Invasive plant species management quick sheet 7, mile-a-minute (Polygonum perfoliatum) (available from https://plantscience.psu.edu/research/projects/vegetative-management/publications/state parksinvasive-species-management-quicksheets/7.-mile-a-minute-polygonum-perfoliatum) (Accessed on $11 / 05 / 2020)$.

Hejda, M., P. Pyšek, and V. Jarošík. 2009. Impact of invasive plants on the species richness, diversity and composition of invaded communities. J. Ecol. 97: 393-403. 
Horncastle, V. J., E. C. Hellgren, P. M. Mayer, A. C. Ganguli, D. M. Engle, and D. M. Leslie. 2005. Implications of invasion by Juniperus virginiana on small mammals in the southern Great Plains. J. Mammal. 86: 1144-1155.

Hough-Goldstein J., Lake E., Reardon R., and Wu Y. 2015. Biology and biological control of mile-aminute weed. Morgantown, WV: USDA Forest Service Forest Health Technology Enterprise Team, FHTET-2008-10.

Hough-Goldstein, J., M. A. Mayer, W. Hudson, G. Robbins, P. Morrison, and R. Reardon. 2009. Monitored releases of Rhinoncomimus latipes (Coleoptera: Curculionidae), a biological control agent of mile-a-minute weed (Persicaria perfoliata), 2004-2008. Biol. Control. 51: 450-457.

Hough-Goldstein, J., M. Schiff, E. Lake, and B. Butterworth. 2008. Impact of the biological control agent Rhinoncomimus latipes (Coleoptera: Curculionidae) on mile-a-minute weed, Persicaria perfoliata, in field cages. Biol. Control. 46: 417-423.

Hudson, W., G. Robbins, J. DeSio, C. Detweiler, R. Strubel, A. Lovero, J. Beetle, and M. Mayer. 2017. Rhinoncomimus latipes (Coleoptera: Curculionidae) as a biological control agent for mile-aminute, Persicaria perfoliata in New Jersey. Annual Report. Phillip Alampi Beneficial Insect Laboratory, Division of Plant Industry, New Jersey.

Huebner, C. D. 2007. Detection and monitoring of invasive exotic plants: a comparison of four sampling methods. Northeast. Nat. 14: 183-206.

Hyatt, L. A., and S. Araki. 2006. Comparative population dynamics of an invading species in its native and novel ranges. Biol. Invasions. 8: 261-275.

Kartzinel, T. R., J. L. Hamrick, C. Wang, A. W. Bowsher, and B. G. P. Quigley. 2015. Heterogeneity of clonal patterns among patches of kudzu, Pueraria Montana var. lobata, an invasive plant. Ann. Bot. 116: 739-750. 
Kohli, R. K., K. S. Dogra, D. R. Batish, and H. P. Singh. 2004. Impact of Invasive Plants on the Structure and Composition of Natural Vegetation of Northwestern Indian Himalayas ${ }^{1}$. Weed Technol. 18: 12961300.

Kruskal J. 1964. Nonmetric multidimensional scaling: a numerical method. Psychometrica 29:115-129.

Kuebbing, S. E., M. A. Nuñez, and D. Simberloff. 2013. Current mismatch between research and conservation efforts: The need to study co-occurring invasive plant species. Biol. Conserv. 160: 121129.

Kumar, V., and A. Ditommaso. 2005. Mile-a-minute (Polygonum perfoliatum): an increasingly problematic invasive species. Weed Technol. 19: 1071-1077.

Lake, E. C., J. Hough-Goldstein, and V. D’Amico. 2014. Integrating management techniques to restore sites invaded by mile-a-minute weed, Persicaria perfoliata. Restor. Ecol. 22: 127-133.

Lake, E. C., J. Hough-Goldstein, K. J. Shropshire, and V. D’Amico. 2011. Establishment and dispersal of the biological control weevil Rhinoncomimus latipes on mile-a-minute weed, Persicaria perfoliata. Biol. Control. 58: 294-301.

Leicht-Young, S. A., H. O'Donnell, A. M. Latimer, and J. A. Silander. 2009. Effects of an invasive plant species, Celastrus orbiculatus, on soil composition and processes. Am. Midl. Nat. 161: 219-231.

Marble, S. C., C. H. Gilliam, G. R. Wehtje, and M. Samuel-Foo. 2013. Early postemergence control of Yellow Woodsorrel (Oxalis stricta) with Residual Herbicides. Weed Technol. 27: 347-351.

Maron, J. L., and M. Marler. 2008. Field-based competitive impacts between invaders and natives at varying resource supply. J. Ecol. 96: 1187-1197.

Mason, T. J., and K. French. 2007. Management regimes for a plant invader differentially impact resident communities. Biol. Conserv. 136: 246-259. 
McCune B. and J. Grace. 2002. Analysis of ecological communities. MJM Software Design, Gleneden Beach, OR.

McCune B. and J. Grace. 2016. PC-ORD: Multivariate Analysis of Ecological Data, Version 7. MjM Software Design, Gleneden Beach, OR.

Molinari, N. A., and C. M. D’Antonio. 2014. Structural, compositional and trait differences between native- and non-native-dominated grassland patches. Funct. Ecol. 28: 745-754.

Moroń, D., M. Lenda, P. Skórka, H. Szentgyörgyi, J. Settele, and M. Woyciechowski. 2009. Wild pollinator communities are negatively affected by invasion of alien goldenrods in grassland landscapes. Biol. Conserv. 142: 1322-1332.

Mountain, W. L. 1989. Mile-a-minute (Polygonum perfoliatum L.) update- distribution, biology, and control suggestions. Regul. Hortic. 15: 1976-1979.

Nelson, S. B., J. J. Coon, C. J. Duchardt, J. D. Fischer, S. J. Halsey, A. J. Kranz, C. M. Parker, S. C. Schneider, T. M. Swartz, and J. R. Miller. 2017. Patterns and mechanisms of invasive plant impacts on North American birds: a systematic review. Biol. Invasions. 19: 1547-1563.

Nilsen, E. T., C. D. Huebner, D. E. Carr, and Z. Bao. 2018. Interaction between Ailanthus altissima and native Robinia pseudoacacia in early succession: Implications for forest management. Forests. 9.

Okay J.A.G. 1997. Polygonum perfoliatum: a study of biological and ecological features leading to the formation of a management policy, Ph.D. Dissertation. George Mason University, Fairfax, Virginia.

Oliver J. 1997. Mile-a-minute weed (Polygomun perforliatum L.), an invasive vine in natural and disturbed sites. Castanea 61: 244-251. 
Petrovskaya, N., S. Petrovskii, and W. Zhang. 2017. Patchy, not patchy, or how much patchy? classification of spatial patterns appearing in a model of biological invasion. Math. Model. Nat. Phenom. 12: 208-225.

Pimentel, D., S. McNair, J. Janecka, J. Wightman, C. Simmonds, C. O’Connell, E. Wong, L. Russel, J. Zern, T. Aquino, and T. Tsomondo. 2001. Economic and environmental threats of alien plant, animal, and microbe invasions. Agric. Ecosyst. Environ. 84: 1-20.

Richardson, D. M., P. M. Holmes, K. J. Esler, S. M. Galatowitsch, J. C. Stromberg, S. P. Kirkman, P. Pyšek, and R. J. Hobbs. 2007. Riparian vegetation: degradation, alien plant invasions, and restoration prospects. Divers. Distrib. 13: 126-139.

Richardson, D. M., G. G. Forsyth, and I. A. W. Macdonald. 1989. Reductions in plant species richness under stands of alien trees and shrubs in the fynbos biome. South African For. J. 149: 1-8.

SAS Institute, 2013. The SAS system for Windows. Version 9.4. SAS Institute Inc., Cary, NC.

Smith, J. R., and J. Hough-Goldstein. 2014. Impact of herbivory on mile-a-minute weed (Persicaria perfoliata) seed production and viability. Biol. Control. 76: 60-64.

Standish, R. J., P. A. Williams, A. W. Robertson, N. A. Scott, and D. I. Hedderley. 2004. Invasion by a perennial herb increases decomposition rate and alters nutrient availability in warm temperate lowland forest remnants. Biol. Invasions. 6: 71-81.

Tilman, D. 1999. The ecological consequences of changes in biodiversity: A search for general principles. Ecology 80: 1455-1474.

Vilà, M., and J. Weiner. 2004. Are invasive plant species better competitors than native plant species? Evidence from pair-wise experiments. Oikos 105: 229-238. 
Westman, W. E. 1990. Park management of exotic plant species: problems and issues. Conserv. Biol. 4: 251-260.

Wilcove, D. S., D. Rothstein, J. Dubow, A. Phillips, and E. Losos. 1998. Quantifying threats to imperiled species in the United States: Assessing the relative importance of habitat destruction, alien species, pollution, overexploitation, and disease. Bioscience 48: 607-615.

Wu Y., Reardon R., and J. Ding. 2002. Mile-a-minute weed. In: Van Driesche, R., Lyon, S., Blossey, B., Hoddle, M., and Reardon, R. Biological control of invasive plants in the Eastern United States. USDA Forest Service Publication FHTHT-2002-04. 
Table. 1 Rank of relative importance value of each species high to low in two sites ( $P$. perfoliata excluded).

\section{P. perfoliata excluded}

\begin{tabular}{|c|c|c|c|c|c|c|c|c|}
\hline \multirow[t]{2}{*}{ Rank } & \multicolumn{4}{|c|}{ Jefferson } & \multicolumn{4}{|c|}{ Rogersville } \\
\hline & Dominated & Relative_IV & Nondominated & Relative_IV & Dominated & Relative_IV & Nondominated & Relative_IV \\
\hline 1 & Microstegium vimineum & 3.568 & Microstegium vimineum & 3.741 & Celastrus orbiculatus & 2.556 & Ambrosia artemisiifolia & 2.116 \\
\hline 2 & Persicaria longiseta & 0.651 & Persicaria longiseta & 0.510 & Ambrosia artemisiifolia & 0.910 & Celastrus orbiculatus & 1.681 \\
\hline 3 & Impatiens capensis & 0.535 & Impatiens capensis & 0.462 & Oxalis stricta & 0.903 & Oxalis stricta & 1.172 \\
\hline 4 & Pilea pumila & 0.341 & Pilea pumila & 0.435 & Acalypha rhomboidea & 0.684 & Trifolium pretense & 0.655 \\
\hline 5 & Asclepias syriaca & 0.183 & Rumex obtusifolius & 0.380 & Erechtites hieraciifolius & 0.542 & Erechtites hieraciifolius & 0.640 \\
\hline 6 & Poa saltuensis & 0.165 & Muhlenbergia schreberi & 0.258 & Trifolium pratense & 0.315 & Acalypha rhomboidea & 0.518 \\
\hline 7 & Fallopia scandens & 0.142 & Rosa multiflora & 0.243 & Clematis virginiana & 0.177 & Viola sororia & 0.386 \\
\hline 8 & Ageratina altissima & 0.129 & Vitis vulpina & 0.238 & Viola sororia & 0.162 & Clinopodium vulgare & 0.180 \\
\hline 9 & Rosa multiflora & 0.111 & Viola sororia & 0.229 & Lactuca canadensis & 0.152 & Conyza canadensis & 0.154 \\
\hline 10 & Vitis sp. & 0.073 & Ageratina altissima & 0.228 & Bidens frondosa & 0.083 & Rubus pensilvanicus & 0.150 \\
\hline
\end{tabular}


Table. 2 MRPP results for differences between sites and plot types. ( $A$ : the chance-correct within-group agreement; when all items identical with groups, $A=1$, if heterogeneity within groups equals expectation by chance, $\mathrm{A}=0)(\mathrm{JS}=$ Jefferson; $\mathrm{RV}=$ Rogersville $)$.

\begin{tabular}{lll}
\hline Individual factors & $A$ & $P$ \\
\hline Sites & 0.458 & $<0.00000001$ \\
JS (dominated vs nondominated) & 0.03 & 0.029 \\
RV (dominated vs nondominated) & 0.04 & 0.020 \\
\hline
\end{tabular}


Table. 3 Indicator species with $P<0.05$ in each group. (IV = Indicator value). No indicator species was detected in JS site from ISA, while Ambrosia artemisiifolia from nondominated plots and Celastrus orbiculatus from dominated plots were detected in RV site from ISA.

\begin{tabular}{crr}
\hline Groups & Indicator species & P-value \\
\hline Site $-\mathrm{JS}$ & Microstegium vimineum $(I V=1.000)$ & 0.0001 \\
& Acalypha rhomboidea $(I V=0.734)$ & 0.0002 \\
Ambrosia artemisiifolia $(I V=0.905)$ & 0.0001 \\
Celastrus orbiculatus $(I V=1.000)$ & 0.0001 \\
Site $-\mathrm{RV}$ & Erechtites hieraciifolius $(I V=0.734)$ & 0.0001 \\
& Oxalis stricta $(I V=0.860)$ & 0.0001 \\
& Rubus pensilvanicus $(I V=0.378)$ & 0.0447 \\
Plot types $-\mathrm{RV}$ & Trifolium pretense $(I V=0.694)$ & 0.0001 \\
& In nondominated: Ambrosia artemisifolia $(I V=69.9)$ & 0.0006 \\
& In dominated: Celastrus orbiculatus $(I V=60.3)$ & 0.03 \\
\hline
\end{tabular}



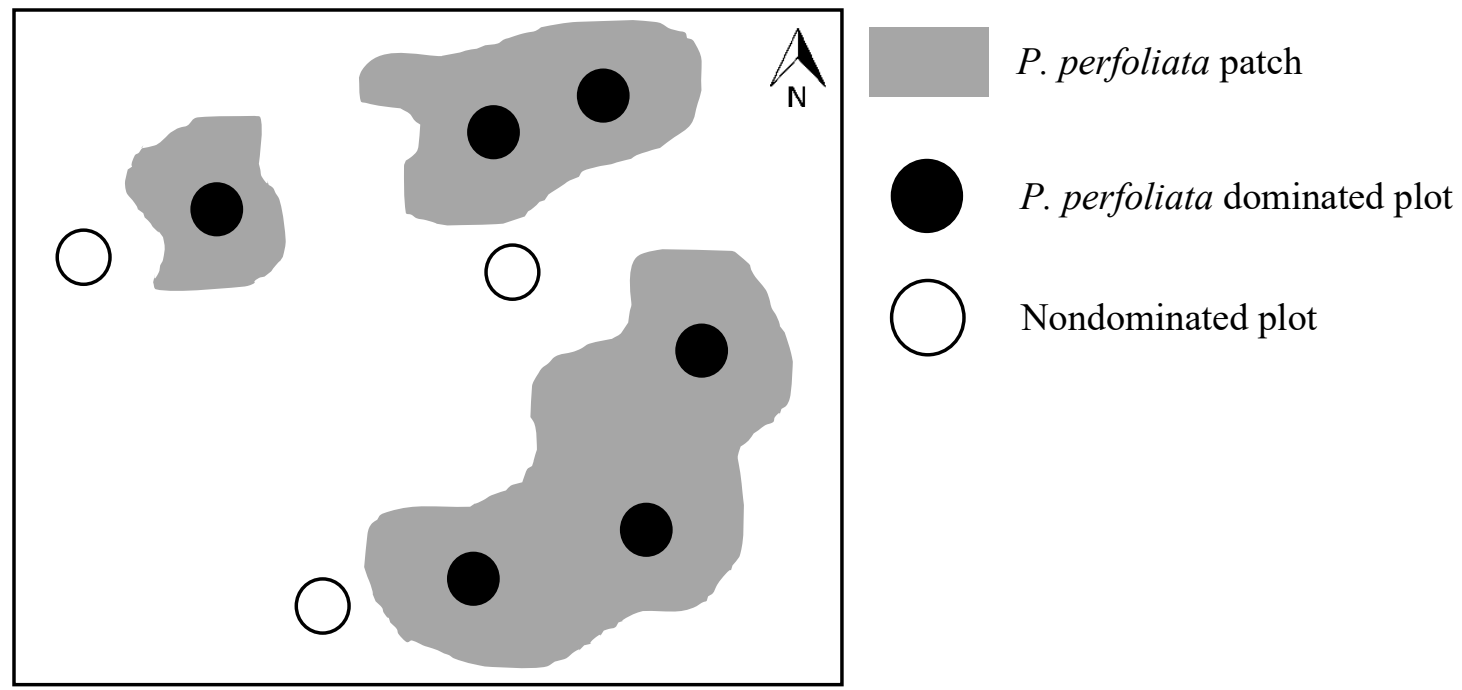

Fig. 1. The plots and patches in various size for potential plots selection. Within patches (Grey) that were $<$ $10 \mathrm{~m}^{2}$, one $1 \mathrm{~m}^{2}$ circular plot was fit for potential vegetation sampling as the $P$. perfoliata dominated plot (Black), and two $1-\mathrm{m}^{2}$ plots were fit in patches $\geq 10 \mathrm{~m}^{2} \&<30 \mathrm{~m}^{2}$, and three $1-\mathrm{m}^{2}$ plots for $\geq 30 \mathrm{~m}^{2}$. After random selection of dominated plots, a nondominated plot (white) was established out of the patch but within 5-m distance. 


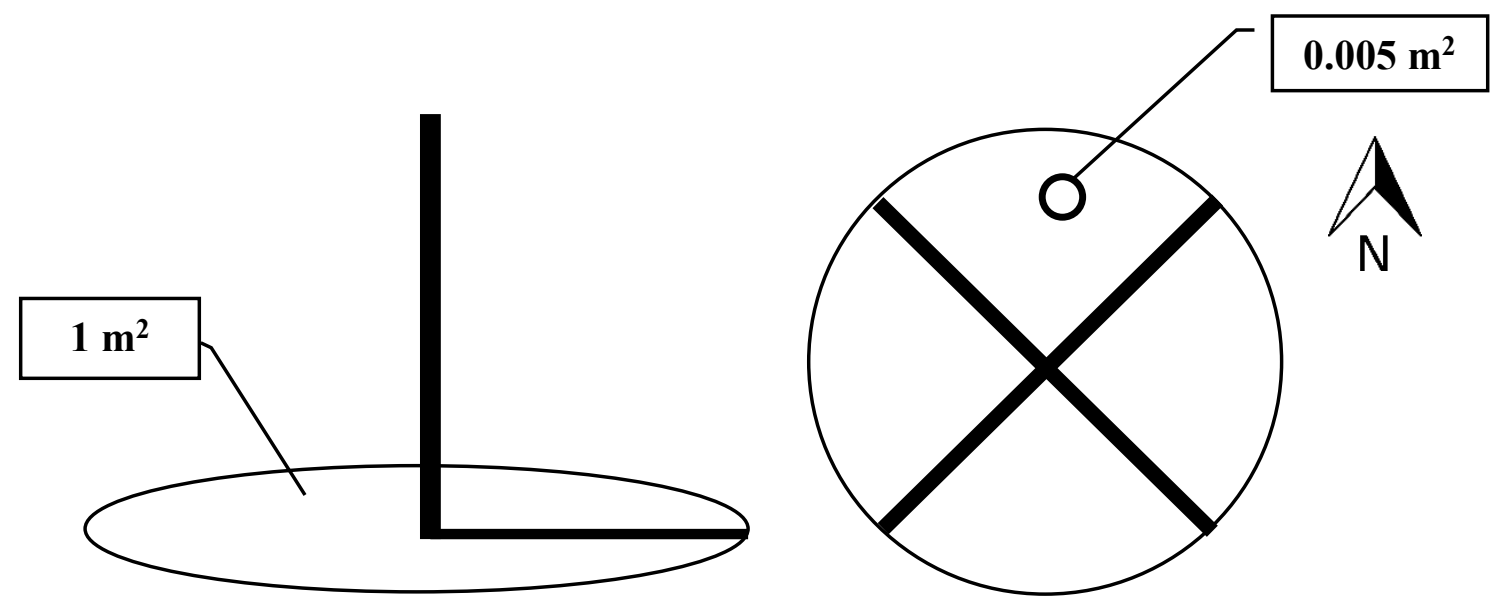

Fig. 2. The schematic diagram of $1 \mathrm{~m}^{2}$ plot and quarters established in the plot. Cover was estimated visually for each plant species by using $0.005 \mathrm{~m}^{2}$ circle. 


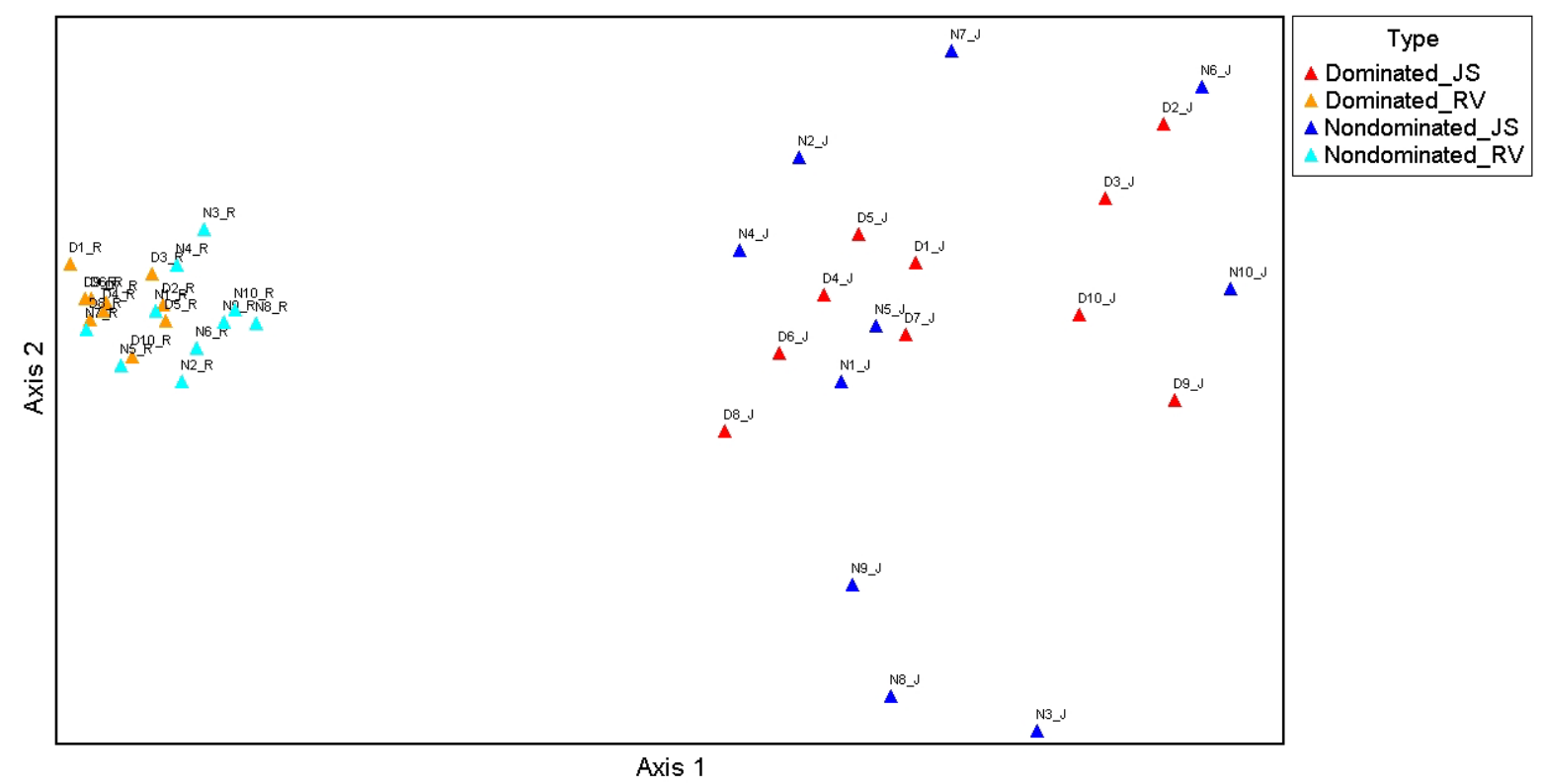

Fig. 3. A stable two-dimensional nonmetric multidimensional scaling ordination for Beals smoothed combined dataset grouped by sites (final NMS stress $=5.93$, final instability $<0.000001, p=0.004$, 250 real and 250 randomized run, Sorensen distance measure). Dissimilarity between dominated and nondominant plots in JS (Dominated plots: Red; Nondominated plots: Blue) is relatively higher than those in RV (Dominated plots: Orange; Nondominated plots: Sky blue). 

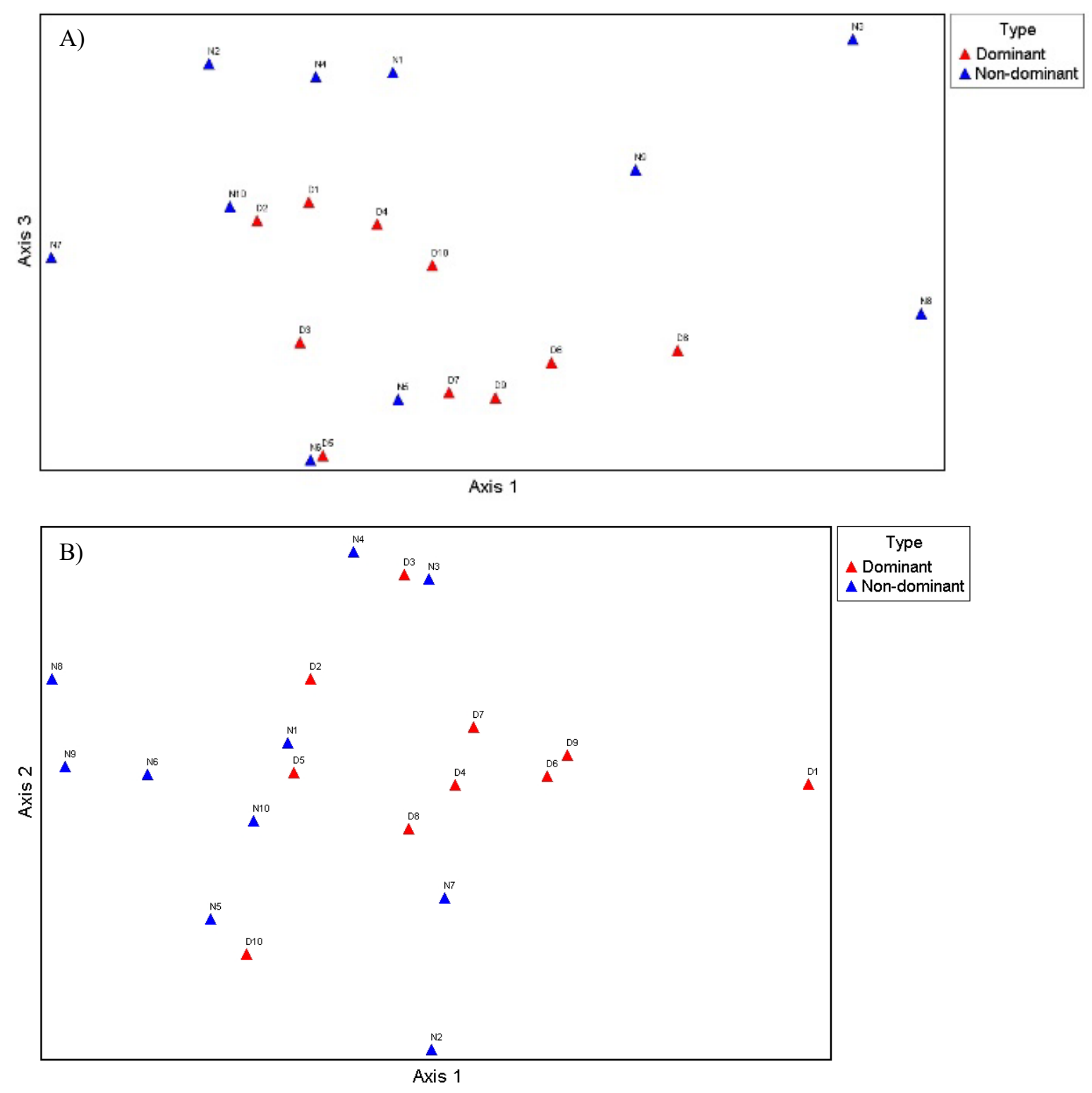

Fig. 4. Separate two-dimensional NMS ordination (A: axis $1 \& 3$ for JS; B: axis $1 \& 2$ for RV) for Beals smoothed data grouped by plot type (JS: final NMS stress $=8.1$, final instability $<0.000001, p=0.004$, 250 real and 250 randomized run, Sorensen distance measure; RV: final NMS stress $=7.2$, final instability $<0.000001, p=0.004250$ real and 250 randomized run, Sorensen distance measure). 

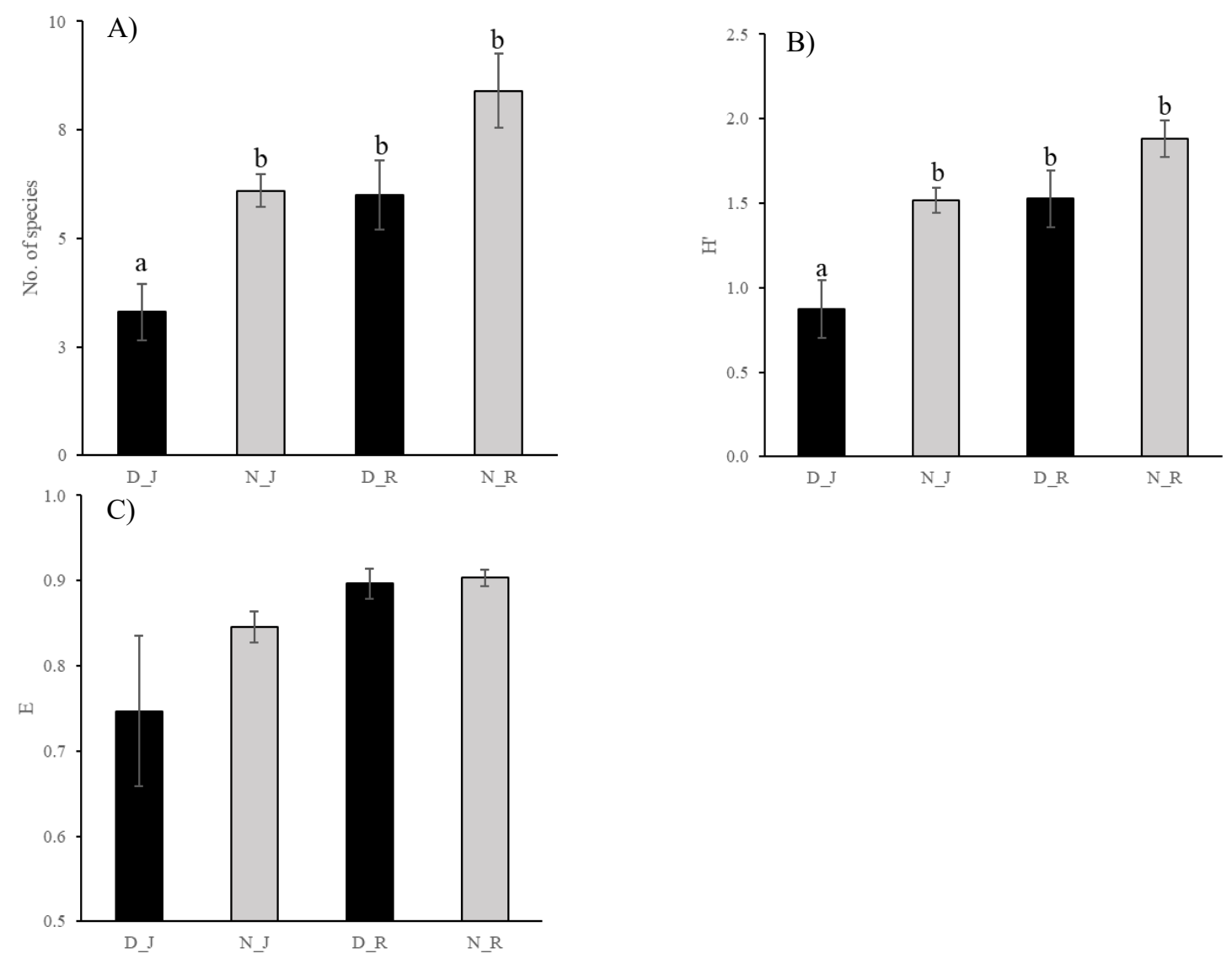

Fig. 5. Mean \pm S.E. of species A) richness, B) Shannon's diversity index, and C) evenness for the summery of combined site data. $\mathrm{D}=\mathrm{P}$. perfoliata dominated; $\mathrm{N}=$ nondominated; $\mathrm{J}=$ Jefferson site, $\mathrm{R}=$ Rogersville site. Different letters indicate statistically significant differences among treatments (ANOVA, HSD). Statistical significance was determined at the alpha level of 0.05. 


\section{Chapter 4: General conclusion}

\section{Conclusion}

The goal of this study is to improve weed management of $P$. perfoliata using UAS as a deployment system of $R$. latipes on $P$. perfoliata patches in hard-to-access areas and to evaluate the plant species composition of invaded sites to determine likely species assemblies or successional trajectories after removal of $P$. perfoliata. Our objectives of this study were to develop spatially-targeted biological control of mile-a-minute weed using $R$. latipes and an unmanned aircraft system and to describe species abundances, richness, diversity, and plant composition in the $P$. perfoliata's dominated plant communities.

The results of this study (Chapter 2) demonstrate the potential of UAS for precision aerial release of $R$. latipes in hard-to-access areas with a patchy distribution of $P$. perfoliata. The bug pod developed in the study was easy to create, easy to load, and fully fabricated with environmentally-friendly material with no negative effects on $R$. latipes mortality and feeding ability. Our study also showed that patchy populations of $P$. perfoliata for targeted aerial release of $R$. latipes could be successfully identified with UAS flown below $15 \mathrm{~m}$ above the ground. These results indicate that aerial detection of $P$. perfoliata and deployment of $R$. latipes for biological control in hard-to-access areas can be accomplished using a rotary-wing UAS.

This study (Chapter 3) considers the impacts of $P$. perfoliata's dominance on species abundance, diversity, and plant composition of invaded sites. The dominance of $P$. perfoliata affects native plant communities negatively and that restoration after any $P$. perfoliata control efforts should be aware of the presence of other dominant exotic and native species. Microstegium vimineum, and A. artemisiifolia at the JS and RV sites, respectively, have a high potential becoming a subsequent dominant species after successful weed management of $P$. perfoliata. These results indicate that understanding potentially coexisting native and exotic species within any infested landscape with a dominant invasive plant targeted for removal will help determine the likelihood of restoration success. 
This study shows that developing an aerial release system for $R$. latipes and detecting $P$. perfoliata patches from the aerial image can support site-specific weed management of $P$. perfoliata in landscape. Additionally, this study showed that $P$. perfoliata may negatively impact the plant communities of the invaded area but there are coexisting dominant exotic and native species that could affect any restoration success of the invaded area upon removal of $P$. perfoliata. These findings suggest that by using targeted biocontrol applications and improved knowledge of likely subsequent dominant species after the removal of $P$. perfoliata, more efficient control of $P$. perfoliata can be achieved. 


\section{Appendices}

Appendix 1. Plant species collected from two sites. JS = Jefferson; RV = Rogersville.

\begin{tabular}{|c|c|c|c|c|}
\hline Species & Family & Origin & $\mathbf{J S}$ & $\mathbf{R V}$ \\
\hline Acalypha rhomboidea Raf. & Euphorbiaceae & Native & & $\mathrm{O}$ \\
\hline Ageratina altissima (L.) King \& H. Rob. & Asteraceae & Native & $\mathrm{O}$ & \\
\hline Ambrosia artemisiifolia $\mathrm{L}$. & Asteraceae & Native & & $\mathrm{O}$ \\
\hline Anemone quinquefolia L. & Ranunculaceae & Native & & $\mathrm{O}$ \\
\hline Apocynum cannabinum $\mathrm{L}$. & Apocynaceae & Native & $\mathrm{O}$ & \\
\hline Asclepias syriaca L. & Apocynaceae & Native & $\mathrm{O}$ & \\
\hline Bidens frondosa L. & Asteraceae & Native & & $\mathrm{O}$ \\
\hline Bromus sp. & Poaceae & Native & & $\mathrm{O}$ \\
\hline Carex laxiflora Lam. & Cyperaceae & Native & $\mathrm{O}$ & \\
\hline Carex sect. Ovales sp. & Cyperaceae & Native & $\mathrm{O}$ & \\
\hline Celastrus orbiculatus Thunb. & Celastraceae & Exotic & & $\mathrm{O}$ \\
\hline Chrysanthemum sp. & Asteraceae & Exotic & & $\mathrm{O}$ \\
\hline Circaea alpina $\mathrm{L}$. & Onagraceae & Native & $\mathrm{O}$ & \\
\hline Cirsium arvense (L.) Scop. & Asteraceae & Exotic & & $\mathrm{O}$ \\
\hline Cirsium vulgare (Savi) Ten. & Asteraceae & Exotic & & $\mathrm{O}$ \\
\hline Clematis virginiana $\mathrm{L}$. & Ranunculaceae & Native & & $\mathrm{O}$ \\
\hline Clinopodium vulgare L. & Lamiaceae & Native & & $\mathrm{O}$ \\
\hline Conyza canadensis (L.) Cronquist & Asteraceae & Native & & $\mathrm{O}$ \\
\hline Cryptotaenia canadensis (L.) DC. & Apiaceae & Native & $\mathrm{O}$ & $\mathrm{O}$ \\
\hline Dichanthelium clandestinum (L.) Gould & Poaceae & Native & $\mathrm{O}$ & \\
\hline Elymus virginicus L. & Poaceae & Native & $\mathrm{O}$ & \\
\hline Erechtites hieraciifolius (L.) Raf. ex DC. & Asteraceae & Native & & $\mathrm{O}$ \\
\hline Fallopia scandens (L.) Holub & Polygonaceae & Native & $\mathrm{O}$ & $\mathrm{O}$ \\
\hline Glyceria spp. & Poaceae & Native & $\mathrm{O}$ & \\
\hline Impatiens capensis Meerb. & Balsaminaceae & Native & $\mathrm{O}$ & $\mathrm{O}$ \\
\hline Lactuca canadensis L. & Asteraceae & Native & & $\mathrm{O}$ \\
\hline Liriodendron tulipifera $\mathrm{L}$. & Magnoliaceae & Native & $\mathrm{O}$ & \\
\hline Microstegium vimineum (Trin.) A. Camus & Poaceae & Exotic & $\mathrm{O}$ & \\
\hline Muhlenbergia schreberi J.F. Gmel. & Poaceae & Native & $\mathrm{O}$ & \\
\hline Oxalis stricta $\mathrm{L}$ & Oxalidaceae & Native & & $\mathrm{O}$ \\
\hline Panicum virgatum $\mathrm{L}$. & Poaceae & Native & $\mathrm{O}$ & \\
\hline Persicaria longiseta (Bruijn) Kitag. & Polygonaceae & Exotic & $\mathrm{O}$ & $\mathrm{O}$ \\
\hline Persicaria perfoliata (L.) H. Gross & Polygonaceae & Exotic & $\mathrm{O}$ & $\mathrm{O}$ \\
\hline Persicaria virginiana (L.) Gaertn. & Polygonaceae & Native & $\mathrm{O}$ & \\
\hline Pilea pumila (L.) A. Gray & Urticaceae & Native & $\mathrm{O}$ & \\
\hline Poa saltuensis Fernald \& Wiegand & Poaceae & Native & $\mathrm{O}$ & \\
\hline Robinia pseudoacacia L. & Fabaceae & Native & $\mathrm{O}$ & \\
\hline Rosa multiflora Thunb. & Rosaceae & Exotic & $\mathrm{O}$ & \\
\hline Rubus allegheniensis Porter & Rosaceae & Native & $\mathrm{O}$ & \\
\hline
\end{tabular}


Rubus pensilvanicus Poir.

Rumex obtusifolius L.

Sambucus nigra spp. canadensis (L.) R. Bolli

Sanicula spp.

Schedonorus pratensis (Huds.) P. Beauv.

Scirpus spp.

Solidago curtisii Torr. \& A. Gray

Symphyotrichum lanceolatum (Willd.) G.L. Nesom

Rosaceae Native O

Polygonaceae Native O

Caprifoliaceae Native O O

Apiaceae Native $\mathrm{O}$

Poaceae Exotic O

Cyperaceae Native $\mathrm{O}$

Asteraceae Native O

Symphyotrichum prenanthoides (Muhl. ex Willd.) G.L. NesomAsteraceae Native $\quad$ O

Trifolium pratense L.

Ulmus rubra Muhl.

Verbesina alternifolia (L.) Britton ex Kearney

Vernonia gigantea (Walter) Trel.

Viola sororia Willd.

Vitis spp.

Fabaceae

Native $\mathrm{O}$

Ulmaceae Native $\mathrm{O}$

Asteraceae Native $\mathrm{O}$

Asteraceae Native O O

Violaceae Native $\mathrm{O} O$

Vitis vulpina L.

Vitaceae Native $\mathrm{O}$

Vitaceae Native $\mathrm{O} O$

